\title{
Review on Light Management by Nanostructures in Chalcopyrite Solar Cells
}

This content has been downloaded from IOPscience. Please scroll down to see the full text.

Download details:

IP Address: 160.45.66.177

This content was downloaded on 27/02/2017 at 12:10

Manuscript version: Accepted Manuscript

Schmid

To cite this article before publication: Schmid, 2017, Semicond. Sci. Technol., at press:

https://doi.org/10.1088/1361-6641/aa59ee

This Accepted Manuscript is: Copyright 2017 IOP Publishing Ltd

During the embargo period (the 12 month period from the publication of the Version of Record of this article), the Accepted Manuscript is fully protected by copyright and cannot be reused or reposted elsewhere.

As the Version of Record of this article is going to be / has been published on a subscription basis, this Accepted Manuscript is available for reuse under a CC BY-NC-ND 3.0 licence after a 12 month embargo period.

After the embargo period, everyone is permitted to use all or part of the original content in this article for non-commercial purposes, provided that they adhere to all the terms of the licence https://creativecommons.org/licences/by-nc-nd/3.0

Although reasonable endeavours have been taken to obtain all necessary permissions from third parties to include their copyrighted content within this article, their full citation and copyright line may not be present in this Accepted Manuscript version. Before using any content from this article, please refer to the Version of Record on IOPscience once published for full citation and copyright details, as permissions will likely be required. All third party content is fully copyright protected, unless specifically stated otherwise in the figure caption in the Version of Record.

When available, you can view the Version of Record for this article at: http://iopscience.iop.org/article/10.1088/1361-6641/aa59ee 


\title{
Review on Light Management by Nanostructures in Chalcopyrite Solar Cells
}

\author{
M. Schmid ${ }^{1,2, *}$ \\ ${ }^{1}$ Helmholtz-Zentrum Berlin, Nanooptische Konzepte für die PV, Hahn-Meitner-Platz 1, 14109 Berlin, \\ Germany \\ 2 Freie Universität Berlin, Department of Physics, Arnimallee 14, 14195 Berlin, Germany \\ * martina.schmid@helmholtz-berlin.de
}

\begin{abstract}
Light management has gained wide interest for various types of solar cells. This paper reviews the application of nanostructures for light management to chalcopyrite (CIGSe) type solar cells. Firstly, the relevance of light management for CIGSe solar cells will be introduced and applicable concepts of nanostructures for absorption enhancement discussed. The development of ultra-thin CIGSe solar cells and examples for nanoparticle fabrication techniques together with their chances and challenges for application to CIGSe will be presented. Particular attention will be paid to nanostructures that have been applied to CIGSe solar cells, revealing many theoretical and some experimental results. Metallic and dielectric nanostructures as well as intrinsic nanotextures will be covered. For the future, combined considerations of optical and electrical properties will gain in importance.
\end{abstract}

\section{Table of content}

1. Introduction

2. Light management in CIGSe solar cells

3.3 Nanostructure fabrication and compatibility with CIGSe solar cells

2.1 Need for light management in CIGSe

2.2 Micro-/macroscopic concepts for light

4. Effects of nanostructures in CIGSe solar cells

management

4.1 Intrinsic texturing

2.3 Nanoscopic concepts for light

4.2 Metallic nanoparticles

management

4.3 Dielectric nanostructures

3. CIGSe solar cell and nanoparticle tuning

4.4 Point contact schemes

3.1 CIGSe solar cell fabrication

5. Discussion and outlook

3.2 Performance of ultra-thin CIGSe solar cells

6. Summary 


\section{Introduction}

Global society is facing a growing demand for energy. With it come risks of global warming and limited amounts of fossil resources, which make it necessary to exploit renewable energy sources on a grand scale. Photovoltaics, the direct conversion of sunlight into electricity, offers great potential for exploiting the largest renewable energy source we have - the sun. The key challenge in photovoltaics is finding technology that provides high conversion efficiency at a low cost. In addition, in the long term there is the important concern of the availability and cost of rare materials, especially when it comes to large terawatt installations.

Thin film solar cells are a promising alternative to bulk silicon wafer-based devices, as they allow to reduce material consumption and manufacturing cost and additionally enhance flexibility for rollto-roll production on bendable substrates. Amongst the thin film technologies, perovskites have recently emerged as a very promising high efficiency material reaching well beyond $20 \%$, yet they remain subject to challenges in stability. Kesterites offer benefits of containing non-toxic, abundant and cheap materials although the efficiencies achieved up to now stayed below 15\%. Chalcopyrites, in particular $\mathrm{Cu}(\mathrm{In}, \mathrm{Ga}) \mathrm{Se}_{2}$ (CIGSe), being investigated for several decades already, have proven particularly successful with a steady increase in stabilized record efficiency, recently reaching 22.6\% [1]. Not just is CIGSe a direct band gap material but it also offers excellent electronic properties and high tolerance against environmental influences like varying illumination intensity or even cosmic radiation [2]. An additional short energy payback time makes CIGSe solar cells predestined for large scale deployment - yet the scarcity and supply risk of contained elements indium and gallium [3] may become a limiting factor for production on the terawatt scale. Therefore, continued minimization of absorber thickness is desirable, simultaneously bringing further reduction in material cost and increased production throughput. With a thinner absorber comes however the challenge of incomplete light absorption which can be tackled by applying nano-optical concepts for light localization inside the absorber layer, thus enhancing absorption. Although numerous publications exist showing the application of nanostructured designs to amorphous and microcrystalline silicon, organic and dye-sensitized solar cells, the topic has only recently started to attract significant attention in the field of CIGSe. A direct transfer of previously investigated structures to CIGSe is not always straight forward due to the differences of CIGSe solar cell structure and fabrication technologies as compared to other devices [4]. This paper reviews the current status of applying nanostructures for light management in CIGSe solar cells. Section 2 is devoted to investigating the need for light management in CIGSe and opposes macroscopic approaches to nano-optical concepts. The following section 3 summarizes the technologies for CIGSe solar cell and nanoparticle fabrication since this background will reveal us the requirements for combined production processes. The section also includes a review on the development of ultra-thin CIGSe solar cells which are a basis for the exploitation of nanooptical concepts. In section 4 the various approaches of nanostructures for absorption enhancement of ultra-thin chalcopyrite solar cells are assembled from literature. They range from intrinsic texturing over metallic nanoparticles to dielectric nanostructures and finally point contact schemes 
addressing electrical in addition to optical challenges. In future, nanostructures combining optical and electrical properties for improving the performance of ultra-thin CIGSe solar cells will gain increased importance.

\section{Light management in CIGSe solar cells}

\subsection{Need for light management in CIGSe}

As in every photovoltaic device the ambition of complete light absorption inside the absorber layer is hindered by losses in reflection, parasitic absorption of contact layers and transmission originating from incomplete absorption of the absorber itself. For CIGSe the reflection of the bare interface air/CIGSe would be $24 \%$ at a wavelength $\lambda=800 \mathrm{~nm}$. By adding the standard front layer stack of CdS/i(ntrinsic)-ZnO/ZnO:Al with typical thicknesses of $100 \mathrm{~nm} / 130 \mathrm{~nm} / 240 \mathrm{~nm}$ the reflection can be reduced to $6 \%$ at $\lambda=800 \mathrm{~nm}$. These and the following calculations were performed using the transfer matrix method and optical/constants as derived from transmission/reflection measurements of realistic thin films [5]. Further reduction of reflection as well as of parasitic absorption can be achieved by layer thickness optimization and material adaptation which we will come back to in the next sub-section. For the typical CIGSe absorber thickness of 2-3 $\mu \mathrm{m}$ incomplete absorption generally doesn't pose any limitation in case of good material quality, yet if the thickness is reduced to below $1 \mu \mathrm{m}$ significant losses occur. Then also imperfect reflection and parasitic absorption of the back contact, which is commonly made from Mo, start to play a major role.

Fig. 1a shows the calculated absorption of a typical Mo/CIGSe/CdS/i-ZnO/ZnO:Al solar cell stack as a function of wavelength for various absorber thicknesses. (Details of the CIGSe solar cell structure will be discussed in sec. 3.1.) Clearly, for the thinner absorbers losses emerge which are most pronounced close to the band gap around $1200 \mathrm{~nm}$ and extend more and more towards shorter wavelengths as the thickness $d$ decreases. The solid black line in Fig. $1 \mathrm{~b}$ plots $j_{\mathrm{sc}}(d)$ and reveals the decrease in short circuit current density with thickness reduction. Despite the observed strong drop, the ratio jsc/d actually keeps on increasing down to $d=50 \mathrm{~nm}$ as shown in Fig. 1c. This improvement of short circuit current density per thickness is the reason why thinner absorbers are favorable for/material saving purposes. In order to overcome losses due to incomplete absorption, mechanisms to enhance the path length of light inside the absorber are required. Simulating a perfect reflector underneath the CIGSe layer leads to the red curve shown in Fig. $1 \mathrm{~b}$. It closely matches $j_{s c}(d / 2)$, the current curve plotted for $d$ replaced by $d / 2$. Further shown are $j_{\mathrm{sc}}(d / 4)$ and $j_{\mathrm{sc}}(d / 8)$ revealing that in case of 8-fold enhancement of path length $99 \%$ of the absorption of a thick CIGSe layer can be reached with $200 \mathrm{~nm}$ CIGSe and still 91\% are feasible for $100 \mathrm{~nm}$ thickness. Considering absorber fabrication processes which rarely allow to fall under $100 \mathrm{~nm}$ layer thickness, an up to 10-fold path length enhancement should be fairly sufficient. In addition to this rough estimation, detailed calculations for $j_{s c}$ enhancement as a function of optical path length inside CIGSe can be found in [6]. 

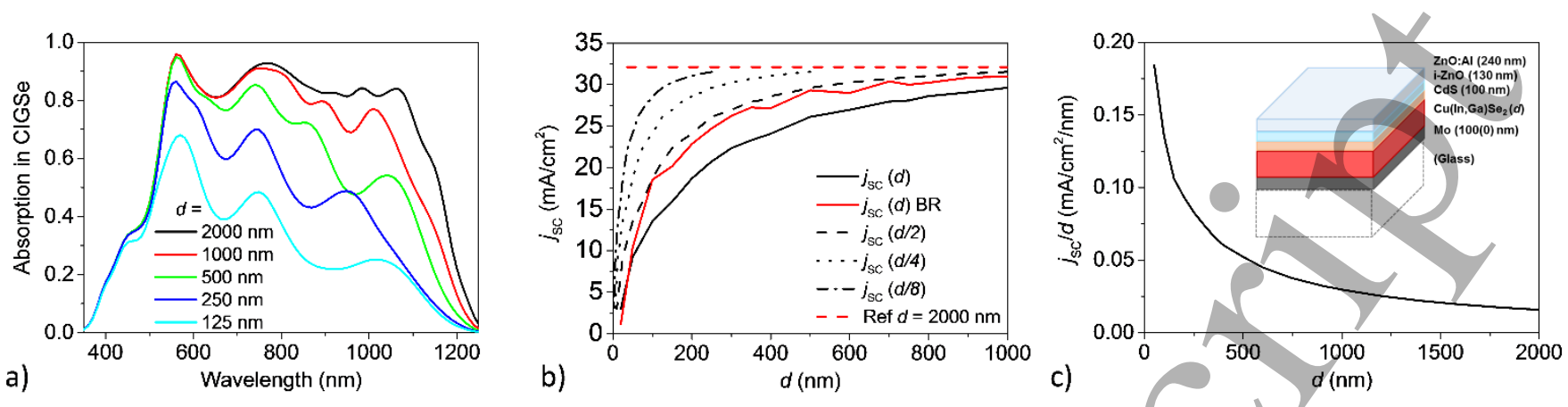

Figure 1: a) Absorption of a CIGSe solar cell for various absorber thicknesses $d$, b) resulting short circuit current density $j_{s c}$, $j_{s c}$ with back reflector $B R$, $j_{s c}$ for $d$ replaced by $d / 2, d / 4$ and $d / 8$ as well as the reference value for the $2000 \mathrm{~nm}$ absorber case, c) short circuit current density per thickness; the inset shows the simulated device structure, glass is added as a dashed block for reference to the experimental structure only where Mo would be $1000 \mathrm{~nm}$ thick.

\subsection{Micro-/macroscopic concepts for light management}

The basic losses occurring due to high front and poor back reflection as pointed out in the previous sub-section can in principle be approached by macro-/microscopic concepts. The front layers $\mathrm{CdS} / \mathrm{i}-\mathrm{ZnO} / \mathrm{ZnO}$ :Al with refractive indices $n=2.29 / 1.93 / 1.78$ at $\lambda=800 \mathrm{~nm}$ already provide a good refractive index gradient to reduce reflection losses from the absorber with $n=2.88$ at $\lambda=800 \mathrm{~nm}$ as we have seen above. The addition of $\mathrm{a} \mathrm{MgF}_{2}$ anti-reflection layer on top with $n=1.38$ at $\lambda=800 \mathrm{~nm}$ further improves the slow gradual transition from air to absorber. In addition to choosing refractive indices of layers such that $n$ of each intermediate layer corresponds approximately to the geometric average of the refractive indices of adjacent layers, the layer thicknesses may be adapted to fulfill the general $\lambda / 4 n$ condition for minimizing reflection. As multiple reflections of the complete thin film stack need to be considered, this however turns out as a coupled optimization problem requiring to adjust all layer thicknesses simultaneously. Optimized values of layer thicknesses for the CdS/i-ZnO/ZnO:Al/MgF 2 stack were given as $d=50 / 50 / 100 / 104 \mathrm{~nm}$ in [7] and as $d=65 / 50 / 90 / 120 \mathrm{~nm}$ in [8], the latter one also optimizing subgap transmission of the - in this case $\mathrm{CuGaSe}_{2}$ top - cell. These values represent minimum layer thicknesses; for electrical reasons thicker layers may be preferable in order to avoid shunting (CdS, i-ZnO) and improve conductivity (ZnO:Al). In a trade off against losses we therefore usually chose $d=100 / 130 / 240 \mathrm{~nm}$ for the front contact layers (no $\mathrm{MgF}_{2}$ ) of ultra-thin devices which are prone to shunting through pinholes in the thin absorber.

The influence of the $\mathrm{ZnO}$ as well as of the CIGSe thickness itself on the device reflection and absorption has also been studied by $\mathrm{Xu}$ et al. [9] and variations as a results of Fabry-Perot resonances were visualized. One result was that a $450 \mathrm{~nm}$ thick absorber may even perform better than a $500 \mathrm{~nm}$ thick one. The authors furthermore showed that front patterning will smoothen interferences and hence increase tolerance in thickness precision. Front texturing was also theoretically investigated by Campa et al. [10] and Dahan et al. [11] and identified to have potential benefits for reduced reflection, yet not as far as increased large angle scattering is concerned 
since the latter one rather increases parasitic absorption in the front contact layers due to the prolonged path lengths [10]. It was also shown that inserting a ZnO intermediate layer between CIGSe and the back contact (Mo or Ag) can significantly improve back reflection; this idea dates back to an earlier publication [12] but still remains questionable from an experimental point of view. A back contact made from a transparent conductive oxide (TCO) and an excellent back reflector at the rear of the glass substrate may be preferable to maintain the electrical performance. Replacing the poorly reflective Mo back contact by alternative materials has been investigated by several groups. W, Ta and $\mathrm{Nb}$ were identified as alternative back contacts with improved reflectivity by Orgassa et al. and a solar cell efficiency surpassing the one on Mo back contact by $0.4 \%$ absolute was shown for $\mathrm{W}$ [13]. In contrast, despite their promising reflectivity $\mathrm{Ti}, \mathrm{V}, \mathrm{Cr}$ and $\mathrm{Mn}$ were found to deteriorate the solar cell performance due to their reactivity with Se during the absorber growth process. Fig. 2a summarizes calculated reflectivity and absorption losses expressed in current densities for Mo, W, Ta, Nb and Ag. Malmström et al. [12] investigated TiN as alternative back contact and also experimentally proved an enhancement in EQE (external quantum efficiency) corresponding to $0.8 \mathrm{~mA} / \mathrm{cm}^{2}$. Highly reflective metals like $\mathrm{Au}$ and $\mathrm{Ag}$ would be most favorable to replace Mo from an optical point of view but pose challenges of diffusion into the absorber at the high CIGSe deposition temperatures. Dahan et al. [11] have proven the benefit of a Au back contact also experimentally by transferring the solar cell onto the Au substrate after growth. This method however remains limited to small solar cell sizes and for large scale applications alternatives have to be investigated. In fig. $2 \mathrm{~b}$ the calculated absorption for an ultrathin $(500 \mathrm{~nm}$ ) CIGSe solar cell with anti-reflection coating, Au back contact and additionally CdS replaced by higher band-gap ZnS is shown.

a)
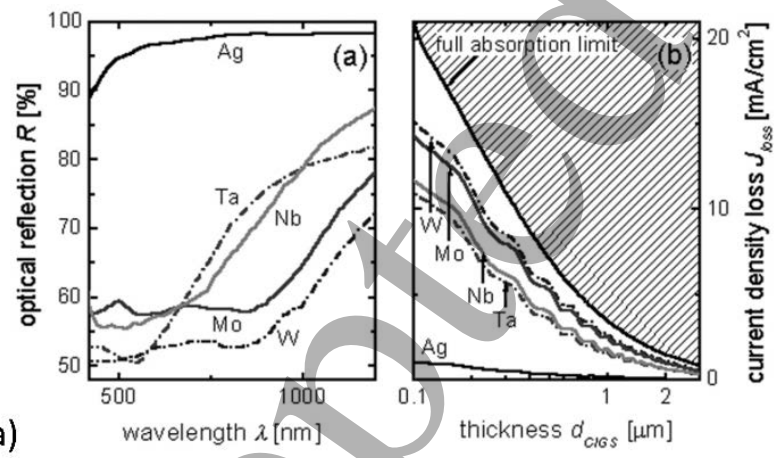

Figure 2: a) Optical reflectivity and simulated absorption losses of different back contact materials in CIGSe solar cells (Reprinted from [13], Copyright (2003), with permission from Elsevier); b) Calculated absorption for ultra-thin $(500 \mathrm{~nm})$ CIGSe solar cell of structure Au/CIGSe/ZnS/ZnMgO/ZnO:Al/anti-reflection coating (Reprinted from [11], with the permission of AIP Publishing.).

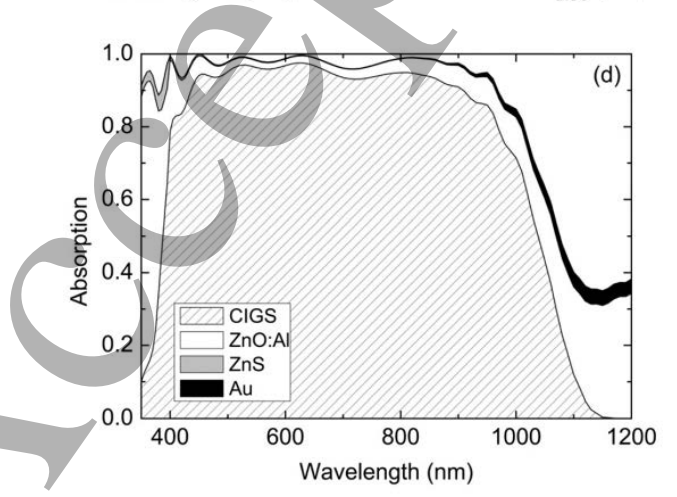




\subsection{Nanoscopic concepts for light management}

Despite the improvement macroscopic approaches for light management can offer, they remain limited by geometrical optics. To further enhance light coupling and localization inside the absorber layer, nanooptical concepts are favored. The underlying three major mechanisms as introduced by Atwater \& Polman [14] and summarized in fig. 3 are: a) nanoparticles rescatter absorbed light under a variety of angles including in particular large angles surpassing the angle of total reflection which can thus lead to light trapping inside a thin layer; b) in the immediate vicinity of the nanoparticles light is localized and the enhanced field strength can contribute to absorption enhancement if the absorber is in close contact with the nanoparticles; c) regularly arranged nanoparticles can couple light into waveguide modes and hence redirect normally incident light into the horizontal direction, i.e. inside the solar cell layers.

a)

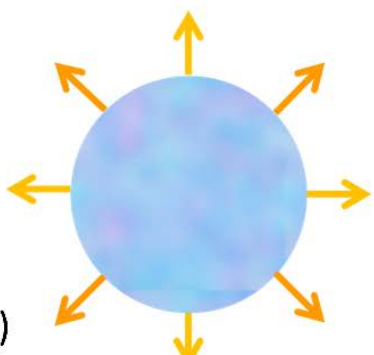

b)

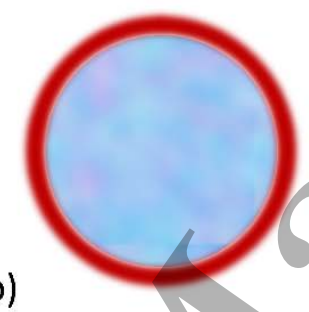

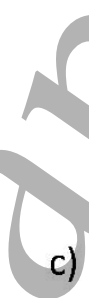
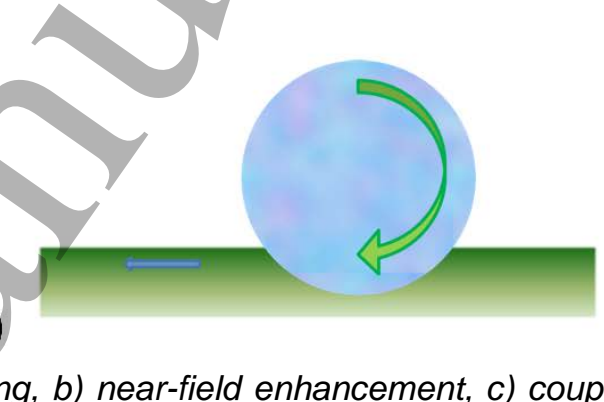

Figure 3: Effects of nanoparticle - light interaction: a) Scattering, b) near-field enhancement, c) coupling into waveguide modes.

Fig. 4 exemplifies the working mechanisms of nanoparticle - light interaction and also compares the behavior of metallic versus dielectric nanostructures. In fig. $4 \mathrm{a}$ a Ag nanoparticle (Ag refractive index data from Palik [15]) with radius $r=75 \mathrm{~nm}$ in air and on a ZnO:Al interface is investigated. Light is always incident from top and an individual nanoparticle is simulated using the finiteelement package JCMsuite [16] with perfectly matched layer (PML) boundary conditions. At the resonance in scattering occurring at $480 \mathrm{~nm}$ wavelength, the electric near field depicted in the center picture clearly reveals localization at the interface. This observation correlates well with the favored forwards scattering observed in the far field, see the angular scattering distribution given in the right picture. Asides the pronounced forwards directivity the angular scattering distribution also reveals side lobes leading to light propagation under large angles with respect to the normal. Metallic nanoparticles on top of a CIGSe solar cell are therefore expected to scatter light towards the thin film stack and direct it into large angles. Yet, the large angular distribution will have diminished once reaching the absorber layer and in addition parasitic absorption of front contact layers and of the metallic nanoparticles themselves occur. Therefore, an integration at the rear of the absorber and in its close vicinity may be favored. Fig. $4 \mathrm{~b}$ exemplarily investigates the same $\mathrm{Ag}$ nanoparticle in $\mathrm{CIGSe}$ and at the interface to $\mathrm{SnO}_{2}: \mathrm{F}$ as an alternative transparent back contact. The dominating scattering resonance in the visible occurring at $\lambda=820 \mathrm{~nm}$ is now the quadrupole resonance - compare the near field picture - and is a result of resonance red-shifting in higher index surrounding. The electric field remains dominantly confined in CIGSe and the angular scattering distribution confirms the preferential scattering towards this higher refractive 
index material as it is typical for metallic nanoparticles. The quadrupole mode also brings a large variety of scattering angles and strong light trapping inside the absorber layer can be expected as the angle of total reflection is clearly surpassed. Despite this highly promising behavior of metallic nanoparticles at the rear of the CIGSe absorber, the experimental realization remains challenging due to Ag stability which we will come back to in sub-section 4.2. A promising alternative are dielectric nanoparticles since (in the case of inorganic materials) they are highly stable and additionally free from parasitic absorption. At the same time they can also show strong scattering [17] and fig. 4c gives the example of an $r=225 \mathrm{~nm} \mathrm{SiO}{ }_{2}$ nanoparticle (constant refractive index $n=1.46$ ) in CIGSe and on the $\mathrm{SnO}_{2}: \mathrm{F}$ interface. The larger radius compared to the metallic nanoparticle had to be chosen to obtain the prominent scattering in the visible. In contrast to the $\mathrm{Ag}$ nanoparticle, the $\mathrm{SiO}_{2}$ nanoparticle reveals a strong forwards scattering even though the refractive index of the substrate is lower than that of the surrounding. The behavior is visible both from the electric near-field and the angular scattering distribution given for $\lambda=720 \mathrm{~nm}$, the latter additionally revealing a reduced scattering into large angles. Here, disadvantages of dielectric nanoparticles can be seen since they are always characterized by strong forwards scattering. The missing large angle scattering can however be compensated by a periodic arrangement of the nanoparticles as shown in fig. $4 \mathrm{~d}$. The pitch is 1.25 times the nanoparticle diameter. A wavelength of $670 \mathrm{~nm}$ was chosen for the representation as it visualizes both the strong focusing behavior, which is typical for dielectric nanoparticles, together with the coupling into waveguide modes that may be deduced from the periodic high intensity field confinement in between the nanoparticles occurring in lateral direction.

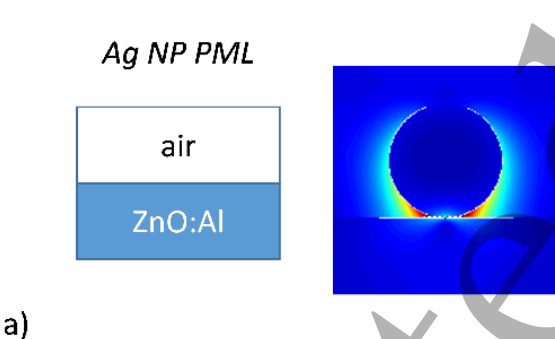

a)

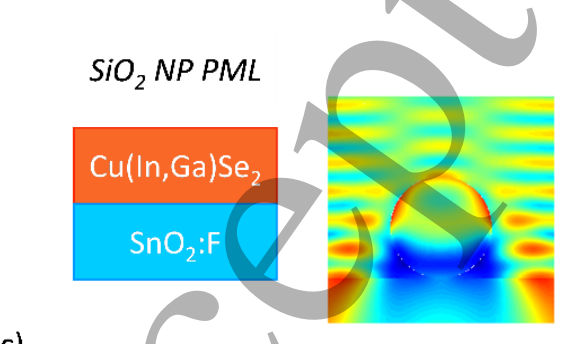

c)

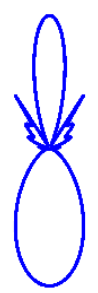

Ag NP PML

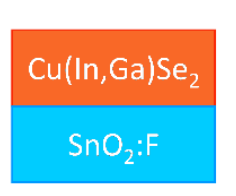

b)
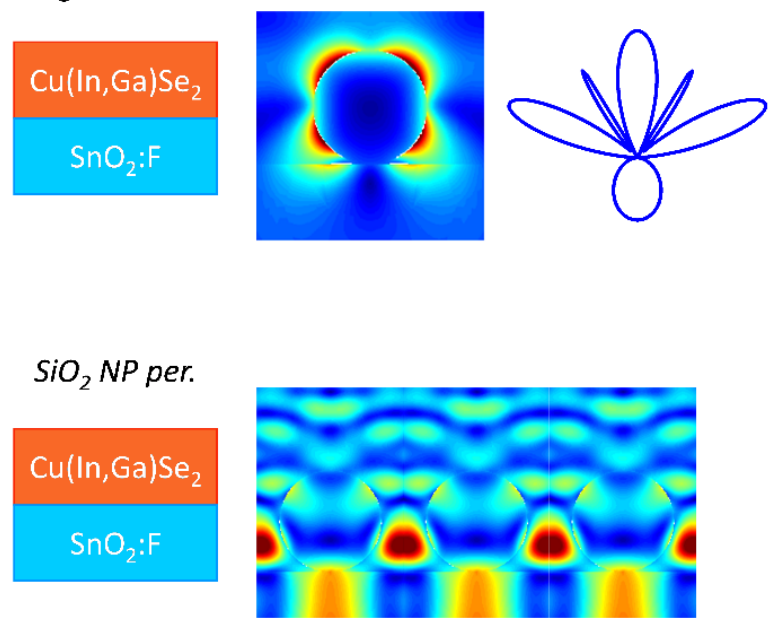

d)

Figure 4: Near-field and scattering of a) isolated (PML) Ag nanoparticle, radius $75 \mathrm{~nm}$ at air - ZnO:Al interface ( $\lambda=480 \mathrm{~nm}$, scale of normalized E-field 0 to 10), b) isolated (PML) Ag nanoparticle, radius $75 \mathrm{~nm}$ at $\mathrm{Cu}(\mathrm{In}, \mathrm{Ga}) \mathrm{Se}_{2}-\mathrm{SnO}_{2}: \mathrm{F}$ interface $(\lambda=820 \mathrm{~nm}$, scale of normalized E-field 0 to 6$\left.), c\right)$ isolated $(P M L) \mathrm{SiO}_{2}$ $(n=1.46, k=0)$ nanoparticle, radius $225 \mathrm{~nm}$ at $\mathrm{Cu}(\mathrm{In}, \mathrm{Ga}) \mathrm{Se}_{2}-\mathrm{SnO}_{2}: \mathrm{F}$ interface $(\lambda=720 \mathrm{~nm}$, scale of normalized E-field 0 to 2), and d) waveguide modes of periodic (pitch 1.25 times nanoparticle diameter) $\mathrm{SiO}_{2}(n=1.46, k=0)$ nanoparticles, radius $225 \mathrm{~nm}$ at $\mathrm{Cu}(\mathrm{In}, \mathrm{Ga}) \mathrm{Se}_{2}-\mathrm{SnO}_{2}: \mathrm{F}$ interface $(\lambda=1180 \mathrm{~nm}$, scale of normalized $E$-field 0 to 4 ). 
Periodically arranged dielectric nanostructures for absorption enhancement have initially been studied for Si solar cells [18] and various configurations reviewed in [19]. Asides Mie resonances also whispering gallery modes of dielectric particles have been investigated for light coupling into Si and GaAs solar cells [20]. Regarding the exploitation of plasmonic resonances for absorption enhancement in solar cells a broad range of publications exists and in [21] an overview on the integration of metallic nanoparticles in silicon and organic devices is given. In [4] we have recently investigated typical nanoparticle configurations for CIGSe solar cells in comparison to other solar cell structures. The literature review on integration of various nanostructures in CIGSe solar cells will follow in section 4.

\section{CIGSe solar cell and nanoparticle tuning}

\subsection{CIGSe solar cell fabrication}

There are numerous articles describing the fabrication and optimization of $\mathrm{Cu}(\mathrm{In}, \mathrm{Ga}) \mathrm{Se}_{2}$ solar cells. These results shall not be reviewed here, but the general device structure and growth methods of the individual layers introduced to facilitate the understanding for possible - or not possible - integration options of nanostructures for light management. For further preparation details the reader is referred to the wide literature which has e.g. been reviewed and referenced in [22].

CIGSe solar cells are usually grown in substrate configuration on glass or alternatively on a flexible substrate like polyimide foil. Superstrate configurations, i.e. the growth of layers in inverted sequence as compared to the following introduction, have been tried, yet due to degradation of the buffer, which in this case is deposited prior to the absorber, have not proven very successful. The common back contact is a several $100 \mathrm{~nm}$ thick layer of Mo deposited mostly by sputtering. Mo is distinguished by its excellent conductivity and high stability also in subsequent high temperature processes. It is assumed to form an ohmic contact with CIGSe via a thin MoSe $\mathrm{C}_{2}$ layer emerging during the absorber growth. A drawback of Mo is its poor reflectivity, yet finding alternative metallic back contacts is challenging since no interdiffusion with CIGSe may occur and a good contact formation is required. Transparent conductive oxides (TCOs) like $\mathrm{SnO}_{2}: \mathrm{F} \mathrm{(FTO),}$ $\mathrm{In}_{2} \mathrm{O}_{3}: \mathrm{Sn}(\mathrm{ITO})$ or $/ \mathrm{In}_{2} \mathrm{O}_{3}: \mathrm{H}(\mathrm{IOH})$ are however alternatives for back contact materials. They can also allow for rear side illumination of the device, giving rise to a sometimes called "backwall superstrate" configuration with rear illumination but no inversion of the layer growth sequence. When growing on TCO back contacts it has to be considered that additional $\mathrm{Na}$, usually in form of $\mathrm{NaF}$, needs to be provided for the formation of high quality CIGSe material. $\mathrm{Na}$, which in the standard configuration diffuses from soda lime glass through the Mo back contact, is well known to support the CIGSe grain formation. Recently also KF has gained significant importance for further efficiency enhancement via increased voltages.

The most crucial deposition step in the device fabrication is the growth of the absorber itself. We can distinguish two major approaches for CIGSe absorber growth which also find application in 
production: the coevaporation and the sequential process. The first one can be conducted in various ways, reaching from a one-step coevaporation of all elements simultaneously over $a$ bilayer, or often called "Boeing process", to the very common 3-stage process of In-Ga/Cu/In-Ga deposition in selenium excess. Multi-stage processes allow to go through a Cu-rich phase which benefits the grain growth and also facilitates fabrication of graded layers. Common to all these coevaporation processes is that they need to be conducted at elevated temperatures of $400-600^{\circ} \mathrm{C}$ held for times in the order of an hour (strong variations may occur depending on lab scale or industrial processes). In contrast, the sequential process can achieve much shorter times at elevated temperatures. The metals $\mathrm{Cu}$, In and $\mathrm{Ga}$ are provide as a precursor stack which is subsequently selenized with elemental selenium or $\mathrm{H}_{2} \mathrm{Se}$ at temperatures of $400-600^{\circ} \mathrm{C}$ as well, yet within times of the order of minutes. Furthermore, such a two-step process also finds application in alternative fabrication approaches where the metal precursor is fabricated e.g. by electrodeposition or from nanoparticle-based solutions/inks. The standard final absorber thickness is $2-3 \mu \mathrm{m}$.

The intrinsic p-type CIGSe absorber is then combined with a so called "window layer" comprising most commonly CdS/i-ZnO/ZnO:Al. Among others, the wide band gap CdS buffer layer helps to improves the band alignment and together with the intrinsic $\mathrm{ZnO}$ layer levels out inhomogeneities of the absorber, thus reducing electrical losses. CdS with a thickness of 50-100 nm is generally formed by chemical bath deposition, a solution based non-vacuum process. Therefore, and in order to replace $\mathrm{Cd}$, alternative buffer layers and according in-line compatible fabrication processes were considered leading to $\mathrm{Zn}(\mathrm{O}, \mathrm{S}), \mathrm{ZnMgO}$ or $\mathrm{In}_{2} \mathrm{~S}_{3}$. Intrinsic $\mathrm{ZnO}$ is deposited next with a thickness of 50-200 nm, generally by sputtering. Finally follows ZnO:Al (AZO) with a thickness of at least $100 \mathrm{~nm}$, in modules of several $100 \mathrm{~nm}$. AZO is the common n-type semiconductor used to complete the pn-junction; an alternative is ITO, or recently also $\mathrm{IOH}$. This highly doped TCO is usually sputtered at room or maximum slightly elevated temperatures $<200^{\circ} \mathrm{C}$ are used in order to avoid damage of the CdS buffer layer and its interdiffusion with CIGSe. Ni/Al grids are added to the solar cells for front contacting.

In summary of the CIGSe solar cell fabrication processing, the following points are important to remember when later discussing the integration of nanostructures:

- The absorber growth happens at elevated temperatures of $400-600^{\circ} \mathrm{C}$ held - depending on the process - for several minutes to hours.

- The front contact is formed by a multilayer system comprising usually CdS/i-ZnO/AZO with a total thickness of at least $200 \mathrm{~nm}$.

- The buffer layer CdS is sensible to high temperatures as degradation and diffusion may occur above $200^{\circ} \mathrm{C}$.

The back contact layer also has to meet thermal and chemical requirements as it experiences the high temperatures during the absorber deposition. 


\subsection{Performance of ultra-thin CIGSe solar cells}

As early as 1988 Birkmire et al. [23] investigated the influence of CulnSe ${ }_{2}$ absorber thickness reduction on the solar cell performance. At that time already bromine etching of chalcopyrite absorbers as a means of thickness and surface roughness reduction was reported. Down to an absorber thickness of $1 \mu \mathrm{m}$ no major losses in open-circuit voltage and light generated currents (when corrected for the changed reflection) were observed.

In 1998 Negami et al. [24] investigated the effect of $\mathrm{Cu}(\mathrm{In}, \mathrm{Ga}) \mathrm{Se}_{2}$ absorber thickness by reducing the deposition time of a 3-stage process. Whilst still obtaining a good performance for $860 \mathrm{~nm}$ absorber thickness, there was a serious breakdown for the devices with $470 \mathrm{~nm}$, which was attributed to the high surface roughness getting in the order of the absorber thickness.

At about the same time the group of W. Shafarman in Delaware started to look in detail into ultrathin CIGSe absorbers. A first drop in efficiency and related solar cell parameters open circuit voltage $V_{\text {oc }}$, short circuit current density $j_{\text {sc }}$ and fill factor $F F$ has been observed around $1 \mu \mathrm{m}$ absorber thickness [25]. Further studies of continued thickness reduction were performed comparing thin as-deposited to etched absorbers [26]. Differences in surface roughness arose and a stable $F F$ for etched absorbers of reduced thickness compared to a drop for as-deposited ones resulted. $j_{\mathrm{Sc}}$ for the two types of samples followed the same trend of reduction with decreasing absorber thickness. A major benefit of ultra-thin CIGSe solar cells could be demonstrated in the so called "backwall superstrate configuration" where the cell is illuminated through the glass substrate and a transparent back contact [27]. In this configuration parasitic losses from the front contact layers, in particular CdS, can be reduced and a back reflector used. Yet, light incidence from the absorber side opposing the pn-junction requires thin absorbers due to limited minority carrier lifetimes and diffusion lengths. Therefore, ultra-thin absorbers $(d \leq 500 \mathrm{~nm}$ ) outperform thick ones in such backwall superstrate devices. 8.8\% efficiency were achieved for $430 \mathrm{~nm}$ absorber thickness in backwall superstrate (using a Ag backreflector) compared to $6.6 \%$ in regular substrate (with Mo back contact) configuration.

The growth of ultra-thin CIGSe absorbers by reduction of deposition time has also been investigated by other groups. At NREL for example Ramanathan et al. [28] used the codeposition and the 3-stage process to obtain efficiencies of $12.6 \%$ for $600 \mathrm{~nm}$ and $9.1 \%$ for $400 \mathrm{~nm}$ absorber thickness, respectively. Detailed analysis revealed both an increasing carrier and defect density with decreasing absorber thickness, which may lead to the lower $V_{o c}$. The question of $V_{O c}$ and $F F$ reduction for thinner absorbers has been and still is a central point of investigation pursued by various groups. Generally, a reduction in $j_{s c}$, resulting at least from incomplete absorption, is obviously expected. As to $V_{\mathrm{OC}}$ and $F F$ different observations have been made. Often $V_{\mathrm{Oc}}$ is mostly unaffected, except for a loss corresponding to the reduction of $j_{\mathrm{sc}}$ according to the diode equation $V_{O C} \approx \frac{A k T}{e} \ln \frac{j_{S C}}{j_{0}}$ with the diode quality factor $A$ and the saturation current density $j_{0}$, as well as the Boltzmann constant $k$, the electron charge $e$ and the temperature $T$.

Yet, FF often reveals a stronger decrease which can be attributed to enhanced back recombination in the ultra-thin devices. This effect has been extensively studied since 2003 by a 
group in Uppsala, comparing e.g. graded and non-graded samples. A high back Ga gradient is known to reduce the back recombination by repelling electrons and was proven beneficial for ultrathin devices by leveraging the losses in FF down to $500 \mathrm{~nm}$ absorber thickness [29]. Electrical investigations also revealed an increased saturation current $I_{0}$, which is governed by recombination, an increased diode quality factor $A$, pointing towards enhanced tunneling recombination, as well as a decreased shunt resistance $R_{\text {sh. }}$. The reduced bulk recombination of ultra-thin absobers is therefore clearly counteracted by an increased interface recombination. Best efficiencies obtained by this group exploiting a back Ga gradient were 12.1\% for $600 \mathrm{~nm}$ [29] and 9.5\% for $300 \mathrm{~nm}$ absorber thickness [30], the latter using $\mathrm{Zn}(\mathrm{O}, \mathrm{S})$ as a buffer which reduces parasitic losses as compared to CdS. Further back contact passivation was obtained by point contacts, which will be discussed in more detail in sec. 4.4, resulting in a maximum efficiency of $13.5 \%$ for a $385 \mathrm{~nm}$ thick absorber. Detailed electrical calculations for the potential of ultra-thin CIGSe solar cells were for example performed by Gloeckler et al. [31].

The above introduced early approach of ultra-thin CIGSe preparation by bromine etching of standard thick absorbers is still followed nowadays in the investigations of a group in France (IRDEP, CNRS). By this approach high quality absorbers (with an even increasing $V_{\text {oc }}$ resulting from the change in band gap upon removal of surface layers) are obtained showing an efficiency of $10.3 \%$ for $500 \mathrm{~nm}$ absorber thickness [32]. These absorbers can serve as a basis for light trapping concepts, which on the micro-/macroscale include front ZnO texturing, replacing $\mathrm{CdS} / \mathrm{ZnnO}$ by less lossy ZnS/ZnMgO and the badly reflecting Mo back contact by Au [11]. The latter optimization step could be reached experimentally by a layer transfer of the ultra-thin absorber to the Au contact, showing high reflectivity and formation of an ohmic contact [33]. The fact that the CIGSe absorber is not grown directly onto the Au contact originates from the challenge of avoiding diffusion of back contact metal during the high temperature absorber deposition process.

Most of the above described ultra-thin absorbers were grown without alteration of the standard growth process conditions (except for deposition times). Yet, an adaptation of the processes to the device thickness can be a key to higher efficiencies. By optimizing rapid thermal processing of metal precursor stacks for ultra-thin absorbers, Kim et al. [34] could achieve elemental depth distributions comparable to the thick devices. This resulted in effiencies as high as $13.7 \%$ for $500 \mathrm{~nm}$ and $9.1 \%$ for $250 \mathrm{~nm}$ absorber thickness compared to a reference value of $14.0 \%$ for $1.9 \mu \mathrm{m}$ thickness. We recently adapted the 3-stage PVD process for ultra-thin absorbers reducing the substrate temperature from 610 to $440^{\circ} \mathrm{C}$ which resulted in a high back Ga gradient and processing temperatures better compatible with the addition of nanostructures. Using this adapted process an increase of efficiency from $9.0 \%$ to $10.6 \%$ for a $460 \mathrm{~nm}$ thick absorber was reported [35]. Subsequent higher efficiencies and an increase to $12.3 \%$ followed upon integration of dielectric nanostructures [36], which will be detailed in sec. 4.3. 
As a summary of the various attempts for fabricating ultra-thin CIGSe solar cells and investigating their performance as a function of thickness, fig. 5 assembles device data obtained by different groups. Where available optimization results are considered as well.

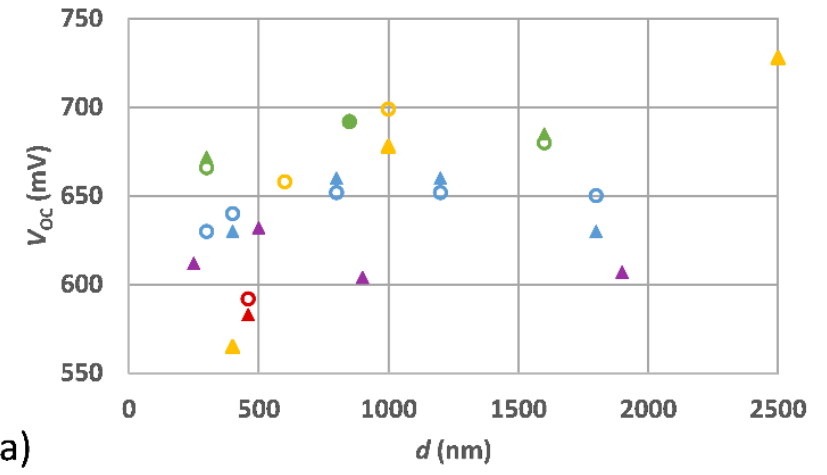

c)

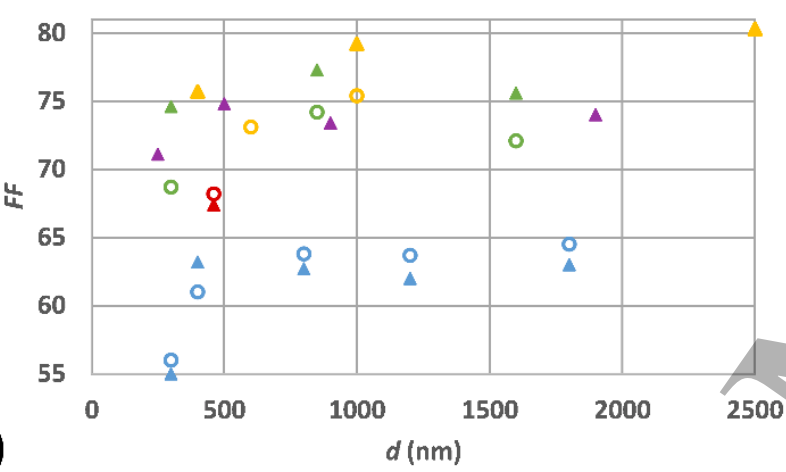

3stage
Ramanathan (NREL)

coevap

$\Delta$ Kim (Delaware)

500

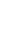

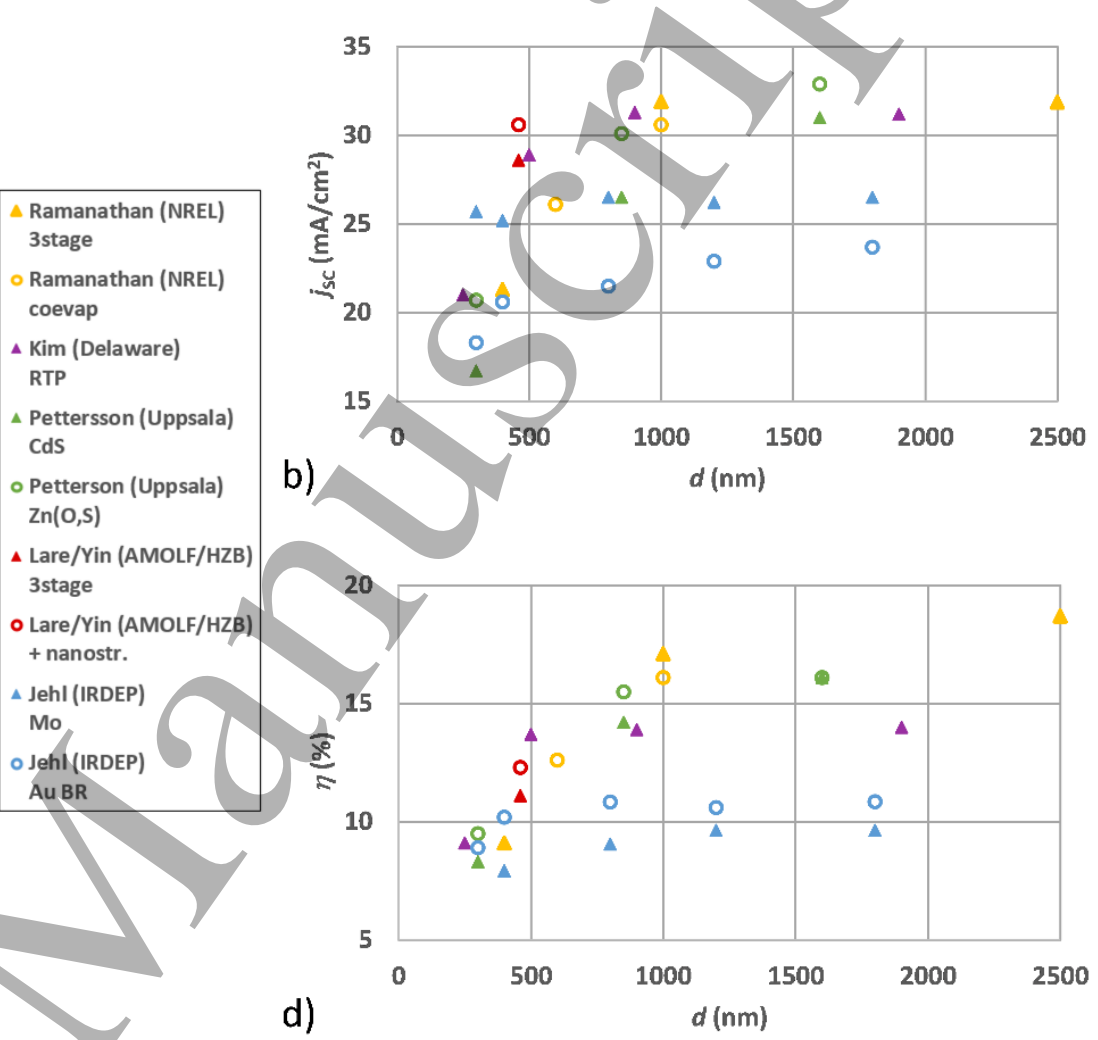

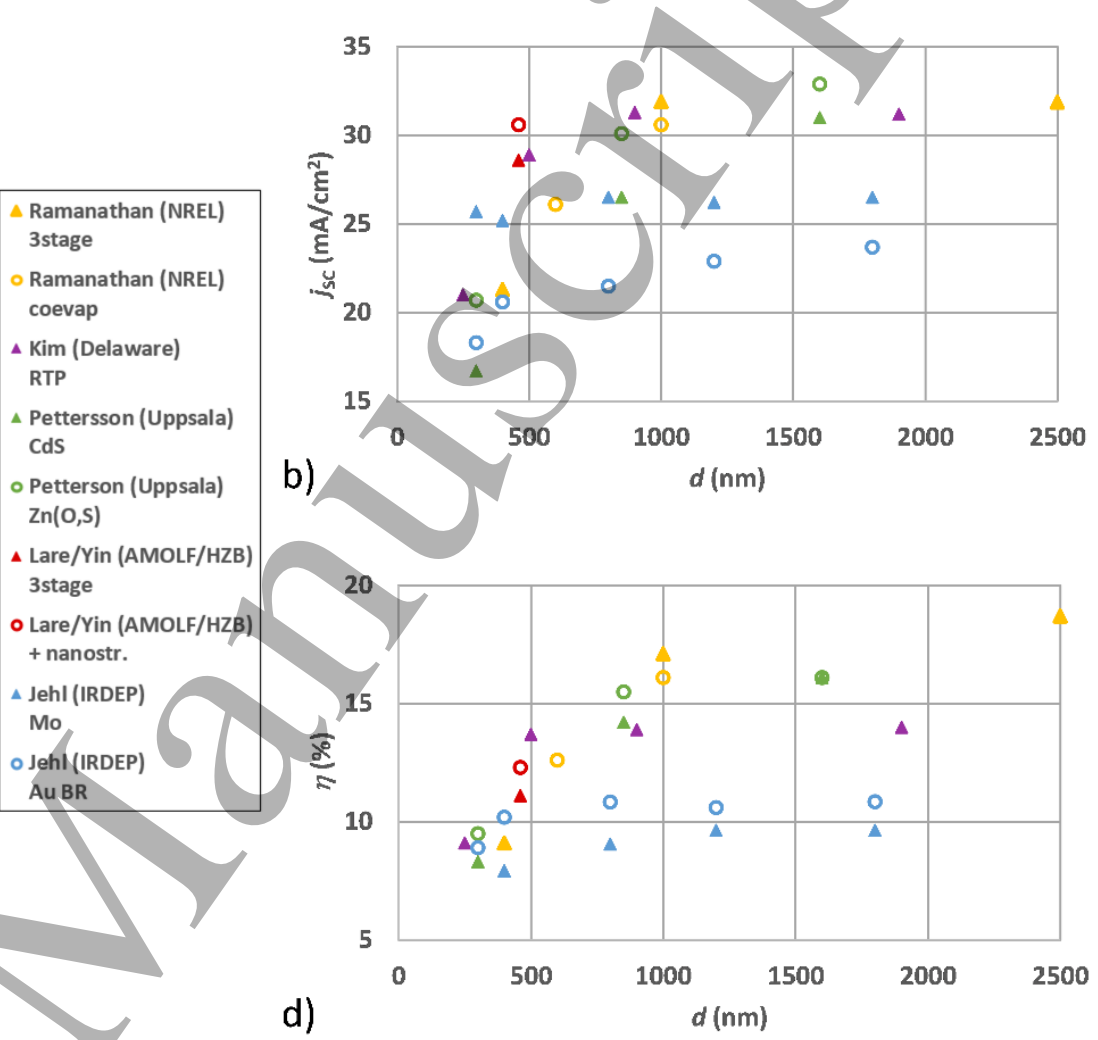

Figure 5: Performance of ultra-thin CIGSe solar cells: a) open circuit voltage, b) short circuit current density, c) fill factor and d) efficiency as a function of absorber thickness. Electrical performance parameters were taken from [28, $30,33,34,36]$.

\subsection{Nanostructure fabrication and compatibility with CIGSe solar cells}

For the preparation of nanostructures a variety of physical and chemical methods exists leading to either random or regular arrangements. A good overview on various fabrication methods is given in [21], which is summarized in the following with an eye on nanostructure control and compatibility with CIGSe solar cell fabrication.

A very easy, scalable and in-líne compatible fabrication approach is the thermal growth of mostly $\mathrm{Ag}$ nanoparticles by evaporation of a thin metal film and subsequent annealing. Typical Ag film thicknesses are $d=5-25 \mathrm{~nm}$, annealing times $t=10-60 \mathrm{~min}$ and annealing temperatures $T=200-500^{\circ} \mathrm{C}[37,38]$. By adjusting these parameters, nanoparticle size, shape and density as well as polydispersity can be tuned, mostly by $d, t$ and $T$, respectively, yet not completely independently. Nanoparticles with diameters above $100 \mathrm{~nm}$ suitable for efficient scattering can be obtained, but they are often accompanied by smaller particles and coverage generally remains high. Thermal growth was one of the initial approaches reported for Ag nanoparticle integration into Si solar cells [39]. When considering the integration into CIGSe solar cells, it however has to 
be considered that $\mathrm{Ag}$ nanoparticles on the back contact will diffuse into the absorber during its high temperature deposition process (and require passivating layers, see sec. 4.2). On the other hand, temperatures above $200^{\circ} \mathrm{C}$ applied for Ag nanoparticle preparation on top of the finished CIGSe solar cell may trigger diffusion of the buffer layer.

A vacuum-free approach separating high temperature preparation steps from the nanoparticle integration goes via chemical synthesis followed by casting methods. Au or Ag nanoparticles can e.g. be obtained by reduction of $\mathrm{HAuCl}_{4}$ with $\mathrm{Na}_{3}$-citrate [40] or $\mathrm{AgNO}_{3}$ with $\mathrm{NaBH}_{4}$ [41]. Seed mediated growth enables an increased control over nanoparticle size and shape [41, 42] which can be adjusted prior to the deposition on the device. Subsequent casting methods include dipping, drop casting or spin coating and enable separate control over particle density. Nanoparticle sizes reached by chemical synthesis are generally smaller than those obtained by physical growth since for larger particles stabilization in solution and avoidance of clustering become challenging. The solvent is the most critical parameter to be considered for nanoparticle integration into the device, yet as it is mostly water or ethanol, this is well compatible with CIGSe solar cells. For the integration adjacent to the absorber layer, a passivating oxide shell is favorable and it is easily accessible in the chemical route as well, see e.g.commonly used Au nanoparticles with $\mathrm{SiO}_{2}$ shells [43].

Two further approaches for nanoparticle formation via chemical processes are spray pyrolysis and electrodeposition. In spray pyrolysis, both metallic [44] and dielectric nanoparticles [45] can be grown from precursor solutions that are nebulized and deposited onto a heated substrate. The nanoparticles form directly on the substrate, unifying nanoparticle growth and deposition in a single process step, yet with improved control over size and density. Recently, a low temperature process for deposition of $\mathrm{Ag}$ nanoparticles from $\mathrm{Ag}$ (hfacac) $\mathrm{PMe}_{3}$ (hfacac: hexafluoroacetylacetona) precursor was shown with substrate temperatures as low as $80^{\circ} \mathrm{C}$ [46]. The solvent involved is just ethanol and compatible with CIGSe solar cells. In the other approach of electrodeposition, the sample is immersed into an aqueous solution containing amongst other components e.g. $\mathrm{NaAuCl}_{4}$ for $\mathrm{Au}$ [47] or $\mathrm{Zn}\left(\mathrm{NO}_{3}\right)_{2}$ for $\mathrm{ZnO}$ formation [48]. Then an electrochemical potential is applied between the sample and a counter electrode to trigger the nanostructure formation. Particles as well as nanorods are accessible and the variation of parameters like concentration, temperature, potential or deposition time allows control over dimensions. A drawback of the electrochemical route is the non-negligible interaction with the CIGSe solar cell which reflects e.g. in stunted growth of $\mathrm{ZnO}$ nanorods on top of $\mathrm{Ni} / \mathrm{Al}$ front contact grids or difficulties in growing CIGSe onto ZnO nanorod coated substrates [49].

Finally, also methods like colloidal/nanosphere lithography or block copolymer lithography are solution based. They offer the great advantage of preparing ordered structures in a simple, scalable and low cost approach. In nanosphere lithography, mostly polystyrene (PS) or poly(methyl methacrylate) (PMMA) beads are dispersed as a monolayer on the substrate by e.g. dip coating, spin coating or immersion. This mask - as it is or with nanosphere sizes adjusted via plasma or reactive ion etching - can then be used in various ways for nanostructure formation. The most popular routes are: deposition of the nanoparticle material onto the mask followed by 
lifting off the beads; deposition of resist onto the beads before lifting them off and deposition of nanoparticle material onto the resist prior to its removal (resulting in the negative of the structure obtained by the previous route); etching of material in between the mask and lifting off the beads afterwards [50]. Depending on the approach, this method gets by with simple solvents like water, ethanol, butanol and low concentrations of acids as well as with etching processes that do not negatively interfere with CIGSe solar cell structures. Therefore, nanosphere lithography offers an easy and compatible approach for ordered nanostructure formation with good control over size, shape and density via adequate choice of bead size and tuning of nanoparticle material deposition. Block copolymer lithography expands the flexibility for nanostructure fabrication based on a combination of two dissimilar polymer chains linked together and assembling in various morphologies, the one of which can be etched more easily than the other [51]. The increased complexity of formation and etching procedures may however bring challenges for integration into CIGSe devices.

The full control over the nanostructure geometrical properties is achieved by conventional lithography techniques. Electron or ion beam lithography enable patterning or direct writing [52] of high resolution nanostructures. Yet, as they are expensive, small scale and may also impact the solar device, they are instead of direct application rather used for the fabrication of molds. In nanoimprint lithography these molds are then stamped into a layer of resist which on its turn is used to generate nanopatterns $[53,54]$. As in nanosphere lithography there are various options, like: deposition of the nanostructure material on top of the patterned resist followed by lifting off the resist; deposition of resist and patterning on top of a metal layer followed by etching of material in between the resist prior to its removal; usage of the patterned resist itself as a nanostructure or overcoated with additional material. The resist, etching and lift-off solvent can be chosen to be compatible with CIGSe solar cell structures, i.e. by using PMMA/solgel as a resist, reactive ion etching and aectone for lift-off [36]. Thus, nanoimprint lithography is a promising approach for generating well-controlled nanostructures and at the same time it is an easy and scalable method. To illustrate nanoparticles obtained by different growth methods, fig. 6 depicts two examples of Ag nanoparticles. The particles in fig. 6a) were fabricated by thermal growth from a $20 \mathrm{~nm}$ thick Ag film annealed at $500^{\circ} \mathrm{C}$ for $20 \mathrm{~min}$, revealing spherically and ellipsoidal nanoparticles with size and density variation. A much more regular arrangement and uniform particle size is obtained by nanosphere lithography: fig. $6 \mathrm{~b}$ visualizes the result of evaporating a $35 \mathrm{~nm}$ thick $\mathrm{Ag}$ film onto a $909 \mathrm{~nm}$ diameter PS sphere mask and annealing the Ag triangles remaining after template removal at $320^{\circ} \mathrm{C}$ for $20 \mathrm{~min}$ to form spherical particles.

In summary of the nanostructure fabrication processes, the following points need to be taken into account when considering the integration into CIGSe solar cells:

- High temperature processes $\left(T>200^{\circ} \mathrm{C}\right)$ for nanostructure formation are detrimental when applied to the finished CIGSe solar cell.

- Metal nanostructures integrated prior to the high temperature CIGSe deposition require passivation by a dielectric spacer. 
a)

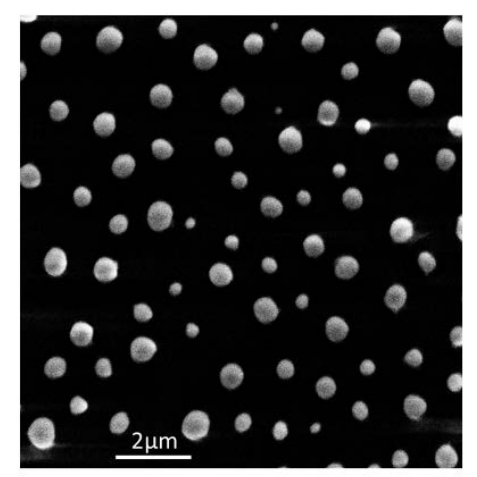

- Nanoparticle growth involving chemical processes should use simple solvents like water, ethanol or butanol to avoid influences on CIGSe solar cells.

- Etching processes (physical or chemical) have to be chosen carefully as well.

b)

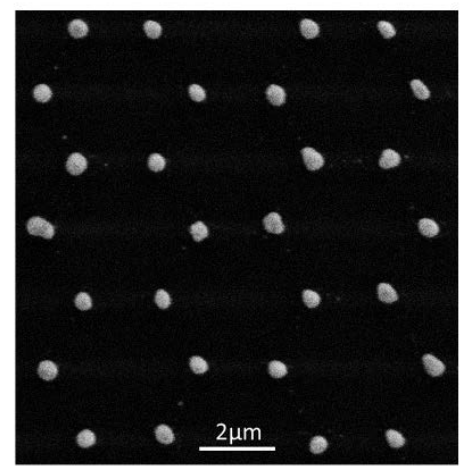

Figure 6: Ag nanoparticles formed a) by thermal growth from a $20 \mathrm{~nm}$ thick $\mathrm{Ag}$ film and subsequent annealing at $500^{\circ} \mathrm{C}$ for $20 \mathrm{~min}$, b) vid nanosphere lithography depositing a $35 \mathrm{~nm}$ thick $\mathrm{Ag}$ film onto a $909 \mathrm{~nm}$ PS sphere template and annealing at $320^{\circ} \mathrm{C}$ for 20 min after template removal.

\section{Effects of nanostructures in CIGSe solar cells}

\subsection{Intrinsic texturing}

The wording intrinsic texturing implies texturing of one of the layers the basic CIGSe solar cell stack consists of. This approach may be a cheap way to introduce nanostructures whilst avoiding to add an additional material related to a further deposition step and possible challenges of compatibility with the other solar cell layers. The investigations of texturing the different layers include various theoretical calculations but a few experimental results exist.

Sec. 2.2 already mentioned the example of front $\mathrm{ZnO}$ texturing smoothening the interferences and hence increasing the tolerance for layer thickness variations [9] and overall reducing reflection [10]. Similarly, photonic structuring of the front (here) ITO layer was identified by Adreani et al. to improve the anti-reflection behavior by better impedance matching at the air/ITO interface [55]. Fig. 7a gives the example of this structures with - according to the sketch on top - dimensions in the range of $100-300 \mathrm{~nm}$. The short circuit current density is expected to show a comparable increase for all investigated absorber layer thicknesses (bottom graph), confirming the antireflection behavior. Yet, no coupling of light via photonic modes to the absorber was mentioned in this context. Also when texturing the CdS layer (and the ZnO layer following exactly the same 
shape) the major effect identified by Hwang et al. [56] was reduced reflection. Comparing conic, parabolic and quadratic shapes, they found the first ones to be most promising and an aspect ratio of 3 (height to base radius) resulted in the minimum reflection of $1 \%$. These structures outperformed the standard $\mathrm{MgF}_{2}$ anti-reflection coating in particular as far as angular tolerance was concerned.

Grating texturing of the rear contact (and subsequently all other layers) was simulated by Onwudinanhti et al. and the excitation of guided modes inside the absorber observed [57]. In contrast to the previously mentioned front contact textures, dimensions in the range of $2 \mu \mathrm{m}$ pitch and $0.5 \mu \mathrm{m}$ height were discussed here. For reduction of parasitic absorption in Mo, TCO back contacts were chosen and the overall optimized structure outperformed the planar thick reference even for $600 \mathrm{~nm}$ absorber thickness.

As far as the above mentioned literature results for front or rear contact textures are concerned, planar CIGSe solar cells served as starting point for extracting realistic refractive indices of layers. The texturing however was only investigated in simulation and therefore the experimental challenge of fabrication processes compatible with CIGSe solar cells has not been addressed. In contrast, the following examples of absorber texturing were confirmed experimentally, pointing out in the first case also the challenges related to fabrication of optical nanostructures: By applying ion-beam milling to CIGSe, nanotip arrays can be obtained. As Liao et al. revealed in [58] the process however leads asides to nanostructure formation also to compositional changes and alteration of surface states. A resulting improvement in solar cell performance can thus not directly be related to an improved anti-reflection behavior as stated previously [59] but rather to the changes in composition and correlated electronic effects. In another example, Wang et al. formed microdome and microhole arrays (MDAs/MHAs) in CIGSe layers using an agarose stamp replicated from a Si template [60]. The stamp was soaked with bromine solution and applied either directly (MHAs) or with additives (MDAs) to the single-step sputtered CIGSe for local etching. Field localization and enhanced carrier generation have been identified from simulations most pronouncedly for the MDAs, compare the top part of Fig. 7b where electric field intensity, absorption, carrier generation rate and resulting photo-generated current are shown. The performance improvement by MHAs and MDAs was also proven experimentally for an approximately $2 \mu \mathrm{m}$ thick CIGSe layer as depicted in Fig. $7 \mathrm{~b}$ bottom part and $11.22 \%$ efficiency obtained for the sample with MDAs. For thinner absorbers, the improvement with absorber texturing was found to be even higher.

Furthermore, Wang et al. [61] have - again theoretically - investigated texturing the CIGSe absorber to nanograting strips deposited on a Ag layer and covered with another thin Ag stripe. This concept already provides the transition to the following sub-section on plasmonic structures and therefore shall be mentioned at the end. Setting asides for the moment all the challenges that will arise when trying to form a device, i.e. forming a pn-junction and avoiding diffusion of Ag into the absorber, the structure is very interesting from light trapping point of view. Whereas at some wavelengths (e.g. $490 \mathrm{~nm}$, see top part of Fig. 7c) the Ag top contact is highly reflective, avoiding light to enter the absorber, there exist wavelengths (e.g. $940 \mathrm{~nm}$, bottom part of Fig. 7c) where 
light is efficiently trapped inside the semiconductor grating of the sandwich structure, boosting the absorption in CIGSe. The exploitation of surface plasmon polaritons for coupling of light inside the absorber layer links to the application of metallic nanoparticles for absorption enhancement.
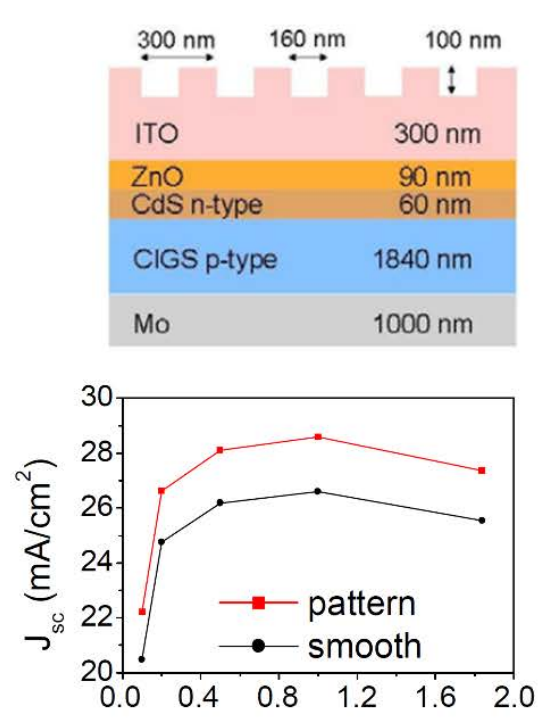

a)

CIGS layer thickness $(\mu \mathrm{m})$
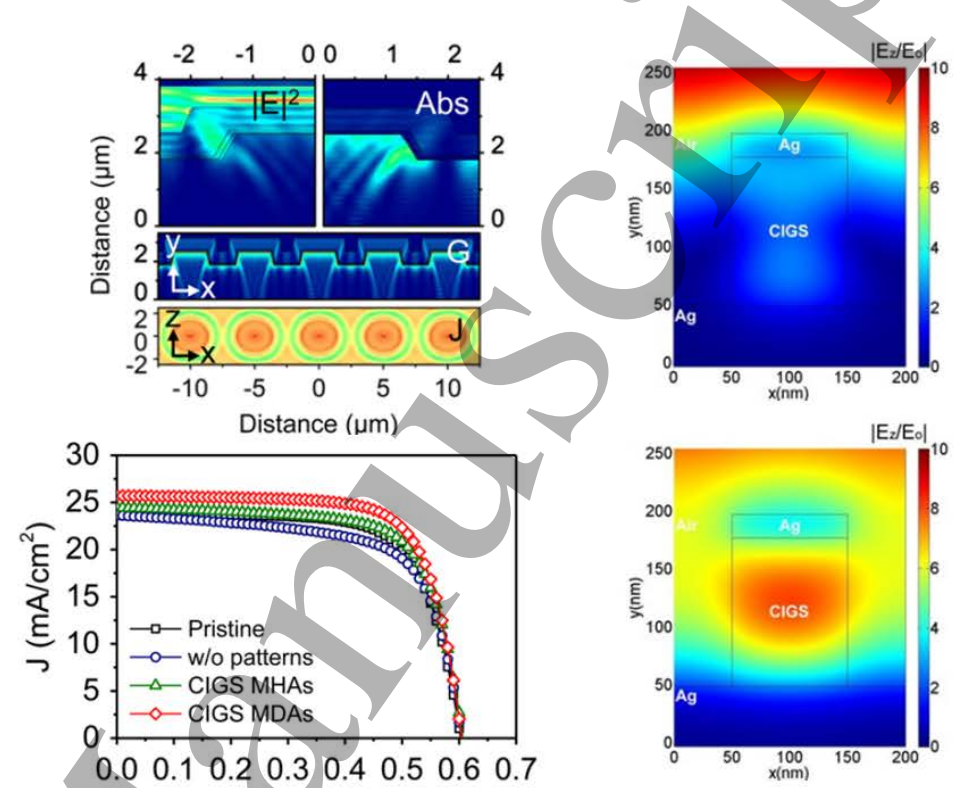

b)

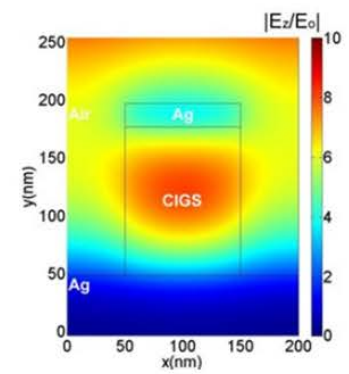

c)

Figure 7: Intrinsic texturing of CIGSe solar cell: a) Front TCO grating structure with dimensions as given (top) and related jsc increase compared to smooth reference (bottom) (Reprinted from [55], with the permission of PVSEC.); b) Simulation of micro dome arrays showing electric field intensity $|E|^{2}$, absorption Abs, carrier generation rate $G$ and photo-generated current $J$ at a wavelength of $875 \mathrm{~nm}$ (top) and jsc increase related to texturing of CIGSe absorber with micro hole and microdome arrays (MHAs/MDAs) (bottom) (Reprinted with permission from [60]. Copyright (2015) American Chemical Society.); c) CIGSe nanograting metal-semiconductor-metal structure with $125 \mathrm{~nm}$ thick CIGSe, width $100 \mathrm{~nm}$ and period $200 \mathrm{~nm}$ : normalized electric field distribution at $490 \mathrm{~nm}$ (top) and $940 \mathrm{~nm}$ wavelength (bottom) (Reprinted from [61], with permission from Optical Society of America.).

\subsection{Metallic nanoparticles}

Following the above introduced CIGSe nanograting strips, the dual grating structure proposed by Le et al. [62] shall be mentioned: both a Ag bottom and a CIGSe top grating were considered, leading to an extended numerical optimization problem which promises a theoretical improvement of $j_{\text {sc }}$ by $24 \%$ for optimized parameters and averaged polarization. Field localization at the $\mathrm{Ag} / \mathrm{CIGSe}$ interface as well as waveguide modes were identified for the $40 \mathrm{~nm}$ thick CIGSe absorber. In [63] Colin et al. showed simulations of a metal-semiconductor-metal structure based on a more realistic CIGSe solar cell stack where also the n-type window layers (in particular CdS) are considered and the Ag nanopattern is embedded in the front $\mathrm{ZnO}$. To address the diffusion problem of the rear $\mathrm{Ag}$ into the absorber layer, an additional $\mathrm{ZnO}$ :Al layer was introduced in between the planar Ag film and CIGSe - an approach which may be feasible in case of substrate transfer. The structure with optimized dimensions as shown at the top of Fig. 8a was identified theoretically to give rise to an $80 \%$ increase in photocurrent for a $100 \mathrm{~nm}$ thick CIGSe layer. The 
absorption improvement as compared to the planar reference with Mo back contact and $400 \mathrm{~nm}$ ZnO:Al window layer is visualized in Fig. 8a bottom part.

By adding metallic structures to the front of the solar cell, reflection losses can never be completely eluded, compare Fig. 7c top part and also Ref. [4]. Thus, the arising reflection together with parasitic absorption losses need to be balanced carefully against benefits resulting from light coupling and scattering. A similar observation was made by Jeng et al. [64] who added Ag and Au nanoparticles of sizes above $100 \mathrm{~nm}$ to CIGSe solar cells by spin coating. The highest efficiency enhancement (2.3\%) was found for the lowest nanoparticle concentration (1\%), underlining the trade-off between metal shadowing and scattering. The difference in enhancement as compared to a similar series on multi-crystalline Si solar cells was attributed to variations in surface roughness and absorber refractive index.

A direct contact of the nanoparticles with the absorber layer is beneficial to exploit additional nearfield effects. Sputtering of Au nanoparticles onto sequentially processed CIGSe performed by Park et al. [65] was observed to lead to a CIGSe/Au nanocomposite layer with improved absorption. An immediate impact of the nanoparticles on the CIGSe absorption in the solar cell cannot be deduced from this experiment but was investigated by Londhe et al. [66] applying chemically synthesized Au nanoparticles by dip coating to electrodeposited CIGSe in a superstrate configuration. The observed increase in $j_{s c}$ was attributed to nanoparticle scattering despite the best performance was observed for the densest nanoparticle coverage. As proven by Chen et al. [67], $10 \mathrm{~nm}$ Au nanoparticles sprayed by air-brush onto inkjet-printed CIGSe could significantly enhance the efficiency from 8.31 to $10.36 \%$, compare Fig. 8 bottom part. The solar cell structure is depicted on top and the position of the small nanoparticles right inside the pn-junction was correlated to enhanced field localization leading to both optical and electrical benefits: not just improved absorption and charge carrier generation are expected but also improved carrier extraction and thus reduced recombination.

On the other hand, metallic nanostructures inside the pn-junction could be expected to constitute additional recombination centers. Therefore, and to avoid reflection losses plus reduced those originating from parasitic absorption, an insertion of nanoparticles underneath the CIGSe layer may be favored. To avoid direct diffusion of in particular Ag into the CIGSe absorber a TCO back contact can be exploited as a spacer layer. In [68] we have shown the expected benefits for such a configuration and revealed in [69] that $\mathrm{Ag}$ nanoparticles underneath an $\ln _{2} \mathrm{O}_{3}$ : Mo layer may persist after rapid thermal processing for CIGS absorber formation. For improved stability also in the case of a longer high-temperature CIGSe growth process, the addition of an ALD-coated $\mathrm{Al}_{2} \mathrm{O}_{3}$ layer was introduced (ALD: atomic layer deposition). In [70] we prove that the structure as depicted in Fig. 8c top part avoids any diffusion of $\mathrm{Ag}$ and can constitute a promising nanostructured back reflector for CIGSe solar cells. The measured absorption enhancement shown in the bottom part of Fig. 8c could partially be attributed to absorption inside CIGSe as deduced from optical simulations of this structure.

As an alternative to passivate the nanoparticles, an absorber layer transfer may avoid the metallic nanostructures having to withstand a high temperature absorber deposition process. Goffard et 
a)

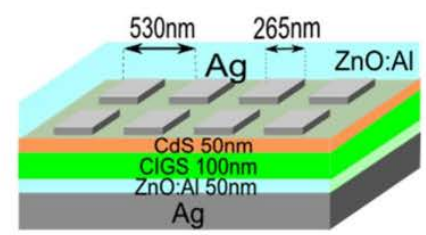

al. [71] have considered metal-dielectric nanostructured back mirrors under this aspect and investigated $\mathrm{Ag}-\mathrm{TiO}_{2}$ gratings on $\mathrm{Ag}$ theoretically and $\mathrm{Au}-\mathrm{TiO}_{2}$ gratings on Au experimentally. A $j_{\mathrm{sc}}$ of $35.9 \mathrm{~mA} / \mathrm{cm}^{2}$ was obtained for a $150 \mathrm{~nm}$ thick CIGSe layer in theory and $16.04 \mathrm{~mA} / \mathrm{cm}^{2}$ for $300 \mathrm{~nm}$ CIGSe in the experiment. The latter corresponds to $2.3 \mathrm{~mA} / \mathrm{cm}^{2} j_{\mathrm{sc}}$ increase compared to the flat mirror. The concept combines metallic and dielectric nanostructures and thus provides the transition to investigating purely dielectric particles in the next sub-section.

b)
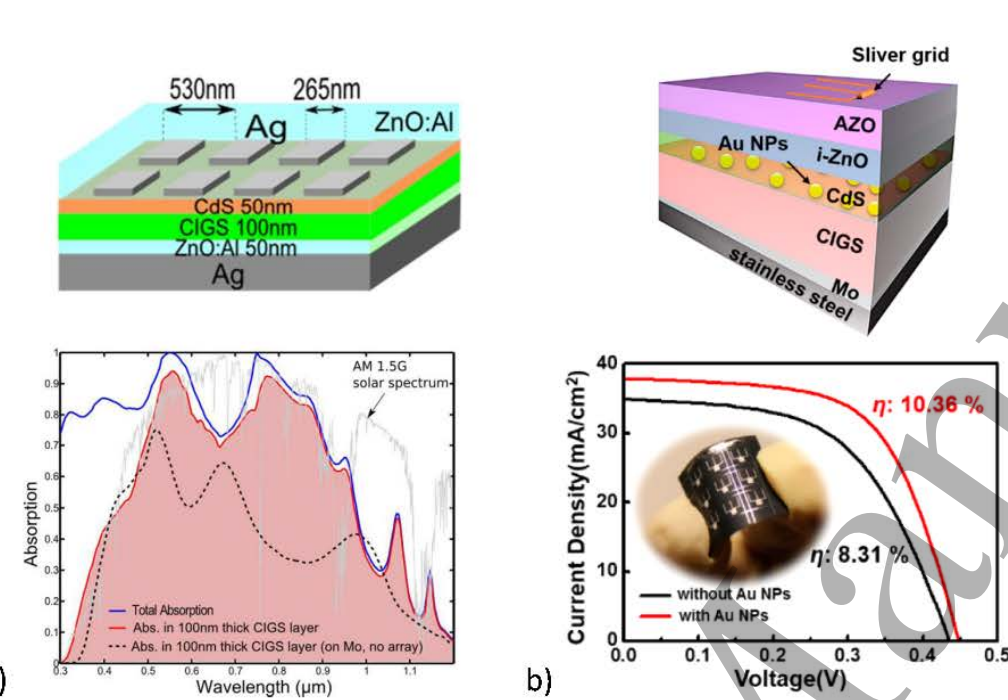

c)

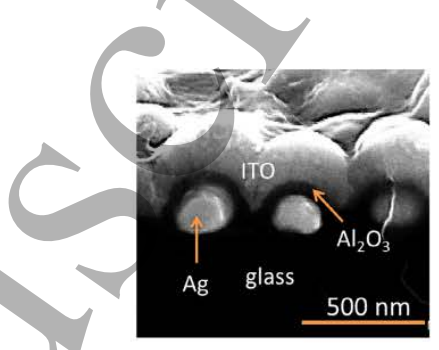

Figure 8: Metallic nanoparticles in CIGSe solar cells: a) Ag nanograting embedded in front ZnO:Al plus Ag back reflector coupling light into $100 \mathrm{~nm}$ CIGSe absorber; structure (top) and absorption enhancement (bottom) as compared to reference with Mo back contact (Reprinted from [63], with the permission of PVSEC.); b) $10 \mathrm{~nm}$ Au nanoparticles at CIGSe/CdS interface (structure on top) leading to performance enhancement as visible from $j V$ characteristics (bottom) (Reprinted with permission from [67]. Copyright (2014) American Chemical Society.); c) Plasmonic back reflector based on Ag nanoparticles underneath ITO passivated by $\mathrm{ALD} \mathrm{Al}_{2} \mathrm{O}_{3}$ (top) and result of integration into a CIGSe solar cell with attribution of absorption enhancement to CIGSe according to modelling (bottom) (Reprinted from [70], Copyright (2015), with permission from Elsevier).

\subsection{Dielectric nanostructures}

The challenges of metallic nanoparticles related to parasitic absorption losses and instability during high temperature processes can be overcome by the use of dielectric structures which are absorption-free and in case of inorganic materials highly stable. Since light coupling via whisphering gallery modes from large nanospheres has successfully been proven for other types of solar cells [72] we investigated $\mathrm{SiO}_{2}$ spheres on top of finished CIGSe solar cells [73]. Resonant excitation was observed for spheres of $600 \mathrm{~nm}$ diameter, compare the top part of Fig. 9a, but the thick front contact layers of the CIGSe solar cell prevent efficient coupling to the absorber. Thus, smaller spheres of approximately $100 \mathrm{~nm}$ diameter turned out more beneficial, acting as efficient anti-reflection coating, see the broadband EQE improvement in Fig. 9a bottom part. This behavior can be compared to the anti-reflection effect of the intrinsic front TCO texturing mentioned in sec. 4,1: in contrast to this structure the dielectric nanospheres require additional material, which 
however can be chosen to be very cheap and completely free from parasitic absorption. Furthermore, self-assembly is an easy, CIGSe-compatible and scalable method, as well as nanoimprint lithography, which can equally be applied. Using the latter approach we also investigated $\mathrm{TiO}_{2}$ nanoparticles on top of finished CIGSe solar cells and confirmed anti-reflection to be the main benefit [36].

ZnO nanorods were investigated by Aé et al. [74] as antireflection coating for CIGSe solar cells and an enhancement in $j_{s c}$ of $5.7 \%$ relative was found. As deduced by Ohm et al. [49], asides the $j$ sc increase, the applied method of electrodeposition for ZnO nanorod growth may however also have negative effects on $V_{O C}$ and $F F$ and the time in the chemical solution should be minimized. Using the ZnO nanorods underneath CIGSe in a backwall superstrate configuration or even bifacial solar cell was investigated as well. Yet, the CIGSe growth by coevaporation on top of the $\mathrm{ZnO}$ nanorods lead to interdiffusion and formation of interface states even at low deposition temperatures. Therefore, highly stable and chemically inert dielectric materials may be preferred for rear-side integration into CIGSe solar cells.

Due to their high chemical stability, $\mathrm{SiO}_{2}$ nanoparticles can without any concerns about diffusion be integrated at the rear of the CIGSe solar cell and in direct contact with the absorber layer. Fig. 9b shows an example of such a structure with conformal overgrowth of layers on top of nanoimprinted particles (top) and the resulting EQE enhancement corresponding to $2.3 \mathrm{~mA} / \mathrm{cm}^{2}$ $j$ sc increase (bottom) [36]. An efficiency of $12.3 \%$ was obtained for the $460 \mathrm{~nm}$ thick absorber. The remaining losses could largely be attributed to parasitic absorption in the Mo back contact so that in a next step we investigated the $\mathrm{SiO}_{2}$ nanoparticles on top of a TCO back contact [75]. Losses in the back contact were significantly reduced and transmitted light could be reflected back into the solar cell structure by a Ag mirror deposited at the rear of the glass substrate, thus preventing any diffusion issues of $\mathrm{Ag}$. A comparison of these ultra-thin (390 nm absorber thickness) CIGSe solar cells to the world record device from [76] yielded $93 \%$ of the short circuit current density. Asides optical effects of the nanoparticles leading to coupling into waveguide modes, also electrical benefits were identified and related to a reduced back barrier and thus improvement of the generally poorly performing CIGSe/ITO contact.

Combined optical and electrical benefits from dielectric nanostructures were further addressed in [77] and [78] where instead of nanoparticles networks were investigated that originated from filling the spaces in between self-assembled nanospheres, compare the structure in Fig. 9c top part. These networks or nanomeshes revealed a broadband EQE enhancement corresponding to $4 \mathrm{~mA} / \mathrm{cm}^{2}$ short circuit current density as given in Fig. 9c bottom part. It was partially ascribed to light coupling and to some extend to reduced interface recombination resulting from the emerging point contact structure. The exploitation of electrical on top of optical effect is a major direction for the further development of nanostructures in CIGSe solar cells and therefore point contact schemes will be addressed in the following sub-section. 

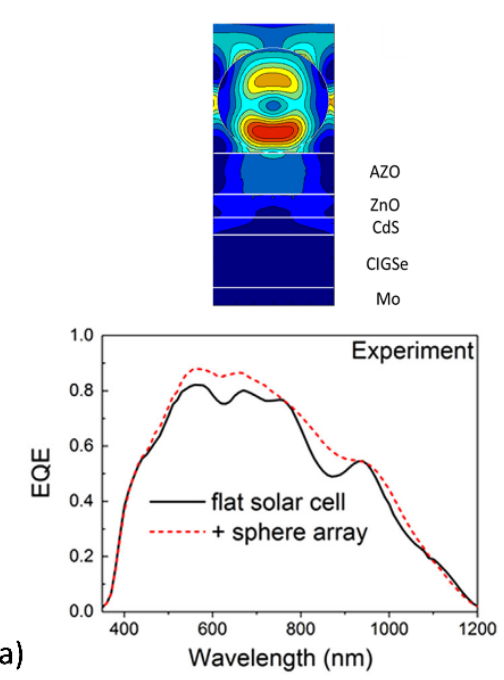

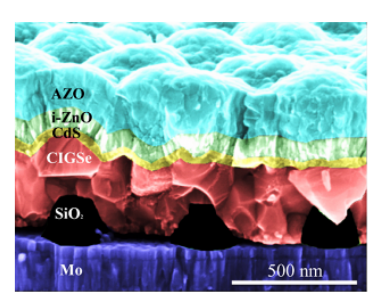

b)

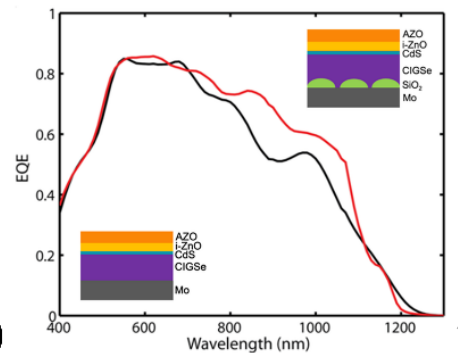

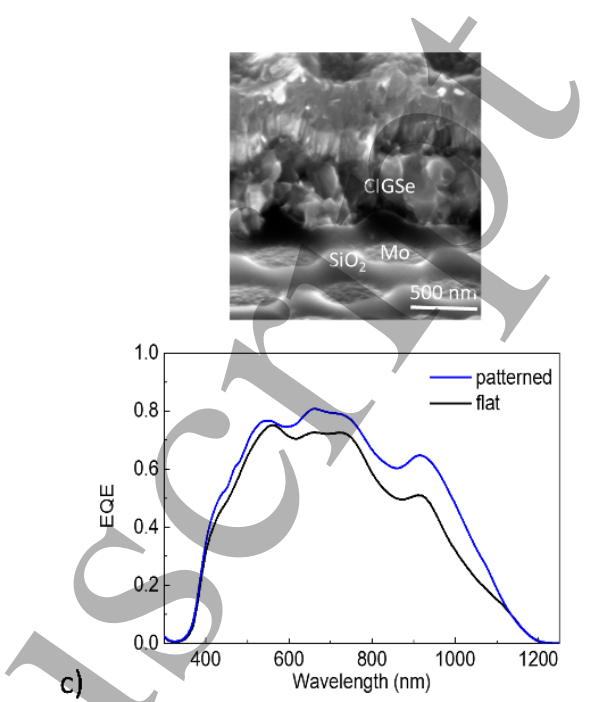

Figure 9: Dielectric nanostructures in CIGSe solar cells: a) Whispering gallery modes of large (600 $\mathrm{nm}$ diameter at $660 \mathrm{~nm}$ wavelength, top) and anti-reflection effect of small (120 nm diameter, bottom) $\mathrm{SiO}_{2}$ nanoparticles on top of CIGSe solar cell (Reprinted from [73], Copyright (2016), with permission from Elsevier); b) $\mathrm{SiO}_{2}$ nanoparticles underneath CIGSe absorber (top) leading to broadband EQE enhancement as compared to planar reference (bottom) (Reprinted from [36, 79], Copyright (2016), with permission from American Chemical Society and Wiley); c) $\mathrm{SiO}_{2}$ network/nanomesh structure underneath CIGSe absorber (top) and related EQE enhancement (bottom) - adapted from (Reprinted from [77], with the permission of SPIE.).

\subsection{Point contact schemes}

As mentioned above, dielectric nanostructures directly underneath the CIGSe absorber may asides their photonic effects also lead to reduced interface recombination. The influence of reduced contacting area or point contact schemes was investigated from an electrical point of view in detail by Vermang et al. In [80] they proposed the formation of a passivation layer with point openings via the deposition of $\mathrm{CdS}$ nanoparticles, overcoating with $\mathrm{Al}_{2} \mathrm{O}_{3}$ and subsequent removal of the nanoparticles. The point contact diameter was in the range of a few hundred $\mathrm{nm}$ and the spacing of the order of few $\mu$ m allowing for complete carrier collection. $\mathrm{Al}_{2} \mathrm{O}_{3}$ was chosen due to its excellent passivation properties resulting from a high density of negative charges. In addition to the electrical effects of reduced interface recombination also an improved rear surface reflectivity was identified which could be further improved by choosing a $\mathrm{MgF}_{2} / \mathrm{Al}_{2} \mathrm{O}_{3}$ bilayer with only a thin $\mathrm{Al}_{2} \mathrm{O}_{3}$ layer providing the required electrical interface properties [81]. The application of the $\mathrm{Al}_{2} \mathrm{O}_{3}$ passivation layer conjoint with scattering Mo nanoparticles to ultra-thin CIGSe solar cells was shown in [82] (see Fig. 10a) and 8.8\% efficiency obtained for a $380 \mathrm{~nm}$ thick CIGSe absorber with single-graded $\mathrm{Ga}$ content. A separate investigation of microstructured $\mathrm{MgF}_{2}$ and $\mathrm{Al}_{2} \mathrm{O}_{3}$ layers as back contact passivation was performed by Casper et al. [83] and significant improvement observed even for point contact spacings in the order of $10 \mu \mathrm{m}$.

The idea of point contacting schemes goes back to Si passivated emitter rear cells (PERC) and thus even prior to the investigation of back surface passivation of CIGSe cells, a similar point contact scheme has been proposed by Allsop et al. [84] for the front CdS/CIGSe interface, see 
Fig. 10b. In a theoretical investigation, point openings of a few $\mathrm{nm}$ radius were identified most beneficial and the spacing chosen in the $\mu \mathrm{m}$-range. $5 \%$ absolute efficiency increase were expected for the interface passivating point contact structure compared to the planar reference. A proof of concept for the front interface passivation by nanostructures was given by Fu et al. [45] using ILGAR-deposited ZnS nanoparticles for passivation and $a \ln _{2} S_{3}$ buffer layer on top (ILGAR: ion layer gas reaction). This structure outperformed both the $\ln _{2} S_{3}$ reference without $Z n S$ nanodots as well as the standard CdS buffer layer. When investigating point contact structures interface defect density, recombination paths and band alignment have to be considered carefully. These electrical properties add to the optical considerations when a joint concept is aspired and will give rise to many interesting structures for further research.

Additionally benefiting from chemical changes that may occur with nanostructure formation, an extended space of optimization is opened. Recently, Reinhard et al. [85] have proposed the selfassembled alkali-salt method to introduce nanostructures on CIGSe or as template for other materials. Since the introduction of alkali salts is also a key for efficiency enhancement when growing CIGSe, coupled effects emerging from material and interface changes and nanostructure formation are to be expected. Thus for the future, combined optical, electrical and chemical effects may play an important role when investigating nanostructures in CIGSe solar cells.

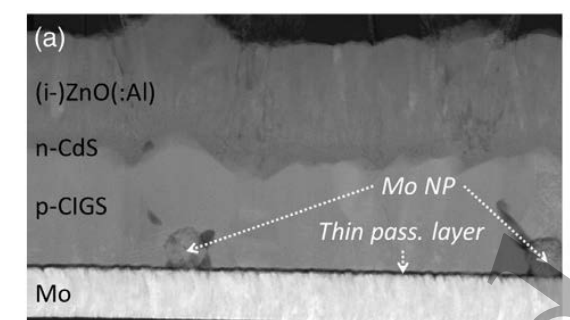

Figure 10: Point contact schemes: a) Mo nanoparticle based point contact at Mo/CIGSe interface (Reprinted from [82], with permission from Elsevier.), b) proposed point contact structure for CIGSe/CdS interface (Reprinted from [84], with the permission of AIP Publishing.).

a)

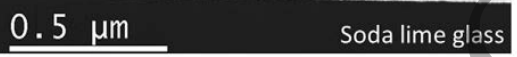

b)

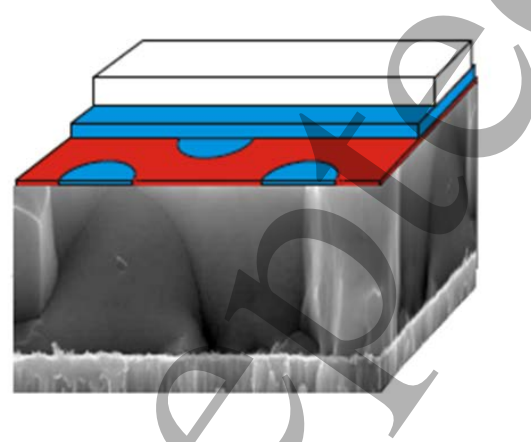

\section{Discussion and outlook}

Many of the above summarized results on nanostructure integration into CIGSe solar cells for light management were of theoretical nature. Therefore, challenges arising from fabrication had not to be dealt with. In this perspective, also metallic nanostructures integrated directly adjacent or even underneath the absorber layer appear promising. Looking at the experimental realization however, metal stability and interdiffusion are serious concerns and means of passivation are required. 
Furthermore, parasitic absorption of metal nanoparticles will always remain an inevitable challenge. For direct integration with the absorber layer and most effective exploitation of photonics effects, dielectric nanostructures may be favorable. They are free from parasitic absorption and can be chosen from highly chemically stable materials grown in processes compatible with CIGSe solar cells. An overview on integration of metallic and dielectric nanoparticles at front and rear interfaces of CIGSe solar cells considering both theoretical expectations and stable experimental realiziation was given in [4]. On the other hand, purposeful changes in chemical properties arising from nanostructure integration may be desired when aiming at improvement of interface states. Considering in addition point contact schemes, leading to reduced interface recombination, dielectric structures are highly promising for future investigations of combined optical and electrical effects.

Several of the cited nanooptical concepts can equally be applied to standard and ultra-thin CIGSe solar cells. This relates in particular to schemes aiming at reduced front interface reflection. Increased rear contact reflectivity in contrast becomes of interest for ultra-thin devices only as does improved light localization and trapping inside the absorber layer. It shall however be mentioned that in case of poor quality absorbers with incomplete absorption even for thick solar cells, light trapping schemes may equally be required. Therefore, nanostructured light control is beneficial for cost reduction in a double sense: firstly for cheap absorber fabrication processes resulting in insufficient absorption due to poor material quality and secondly for ultra-thin absorbers saving material in layers of less than $500 \mathrm{~nm}$ thickness which asides incomplete absorption show good optoelectronic properties. In perspective of the overall aim of highest efficiency at lowest cost, a minimum amount of high quality material paired with sophisticated nanostructures for efficient photon and electron management is desired.

\section{Summary}

In this review nanostructures for light management in chalcopyrite (CIGSe) solar cells were addressed. After presenting the losses in absorption occurring for CIGSe layer thicknesses below $1 \mu \mathrm{m}$, micro-/macroscopic concepts for light management were compared to nanoscopic approaches. Reduction of front and increase of rear interface reflection can be achieved whereat nanostructures additionally amplify lateral light coupling and thus most efficient localization of electric field inside the absorber. The subsequent representation of CIGSe solar cell and nanostructure fabrication aimed at giving a guideline for the development of nanostructures and their integration for light management in CIGSe solar cells. A section was added to review the performance development of ultra-thin CIGSe solar cells as these are the devices that will on the long run fulfill the aim "less material, higher efficiency". The central review on nanostructures integrated into CIGSe solar cells revealed many theoretically and some experimentally promising concepts including intrinsic texturing, metallic nanoparticles and dielectric nanostructures. As discussed in the previous section, challenges arising from experimental realization reduce the amount of feasible configurations. Yet, also purposeful changes in material properties and the 
combination of optical and electrical benefits may be of interested for further research. For the future development of innovative nanostructures for highly efficient CIGSe solar cells the reader shall be inspired by the current state-of-the-art and guided by the experimental conditions arising in practical realization.

\section{Acknowledgment}

M. Song is acknowledged for providing the structures and pictures of fig. 6 as well as is the NanooptiX group for discussion. Simulation results using JCMsuite were obtained at the Berlin Joint Lab for Optical Simulations for Energy Research (BerOSE) of Helmholtz-Zentrum Berlin für Materialien und Energie, Zuse Institute Berlin, and Freie Universität Berlin. Funding was received from the Helmholtz Association for the Young Investigator Group VH-NG-928 within the Initiative and Networking fund.

\section{References}

[1] Zentrum für Sonnenenergie- und Wasserstoff-Forschung Baden-Württemberg 2016 Press Release 09/2016: ZSW Sets New World Record for Thin-film Solar Cells.

[2] Morioka C, Shimazaki K, Kawakita S, Imaizumi M, Yamaguchi H, Takamoto T, Sato S-i, Ohshima T, Nakamura Y, Hirako K and Takahashi M 2011 First flight demonstration of film-laminated InGaP/GaAs and CIGS thin-film solar cells by JAXA's small satellite in LEO Progress in Photovoltaics: Research and Applications 19 825-33

[3] British Geological Survey 2015 Risk list.

[4] Schmid M, Manley P, Ott A, Song M and Yin G 2016 Nanoparticles for Light Management in Ultra-thin Chalcopyrite Solar Cells Journal of Materials Research 313273

[5] Yin G, Merschjann C and Schmid M 2013 The effect of surface roughness on the determination of optical constants of $\mathrm{CulnSe}_{2}$ and $\mathrm{CuGaSe}_{2}$ thin films J.Appl.Phys. 113 213510/1-/6

[6] Krc J, Sever M, Campa A, Lokar Z, Lipovsek B and Topic M 2016 Optical confinement in chalcopyrite based solar cells Thin Solid Films in press

[7] Jackson $P$, Würz R, Rau U, Mattheis J, Kurth $M$, Schlötzer T, Bilger $G$ and Werner J H 2007 High quality baseline for high efficiency, $\mathrm{Cu}\left(\operatorname{In}_{1-\mathrm{x}}, \mathrm{Ga}_{\mathrm{x}}\right) \mathrm{Se}_{2}$ solar cells Progress in Photovoltaics: Research and Applications 15 507-19

[8] Schmid M, Krč J, Klenk R, Topič M and Lux-Steiner M C 2009 Optical modeling of chalcopyrite-based tandems considering realistic layer properties Applied Physics Letters $94053507 / 1-/ 3$

[9] Xu M, Wachters A J, van Deelen J, Mourad M C and Buskens P J 2014 A study on the optics of copper indium gallium (di)selenide (CIGS) solar cells with ultra-thin absorber layers Optics Express 22 A425-37 
[10] Čampa A, Krč J, Malmström J, Edoff M, Smole F and Topič M 2007 The potential of textured front $\mathrm{ZnO}$ and flat TCO/metal back contact to improve optical absorption in thin $\mathrm{Cu}(\mathrm{In}, \mathrm{Ga}) \mathrm{Se}_{2}$ solar cells Thin Solid Films 515 5968-72

[11] Dahan N, Jehl Z, Hildebrandt T, Greffet J J, Guillemoles J F, Lincot D and Naghavi N2012 Optical approaches to improve the photocurrent generation in $\mathrm{Cu}(\mathrm{In}, \mathrm{Ga}) \mathrm{Se}_{2}$ solar cells with absorber thicknesses down to $0.5 \mu \mathrm{m}$ J.Appl.Phys. 112 094902/1-/7

[12] Malmström J, Lundberg $\mathrm{O}$ and Stolt L 2003 Potential for Light Trapping in $\mathrm{Cu}(\mathrm{In}, \mathrm{Ga}) \mathrm{Se}_{2}$ Solar Cells. In: 3rd World Conference on Photovoltaic Energy Conversion 344 - 7

[13] Orgassa K, Schock H W and Werner J H 2003 Alternative back contact materials for thin film Cu(In,Ga)Se ${ }_{2}$ solar cells Thin Solid Films 431-432 387-91

[14] Atwater H A and Polman A 2010 Plasmonics for improved photovoltaic devices Nature Materials 9 205-13

[15] Palik E D 1985 Handbook of optical constants of solids (Orlando: Academic Press)

[16] JCMwave GmbH 2016 JCMSuite Software.

[17] Schmid M, Andrae P and Manley P 2014 Plasmonic and photonic scattering and near fields of nanoparticles Nanoscale research letters 9 50/1-/9

[18] van Lare C, Lenzmann F, Verschuuren M A and Polman A 2015 Dielectric Scattering Patterns for Efficient Light Trapping in Thin-Film Solar Cells Nano Letters 15 4846-52

[19] Brongersma M L, Cui Y and Fan S 2014 Light management for photovoltaics using highindex nanostructures Nature Materials 13 451-60

[20] Grandidier J, Callahan D M, Munday J N and Atwater H A 2012 Gallium Arsenide Solar Cell Absorption Enhancement Using Whispering GalleryModes of Dielectric Nanospheres IEEE Journal of Photovoltaics 2 123-8

[21] Gu M, Ouyang Z, Jia B, Stokes N, Chen X, Fahim N, Li X, Ventura M J and Shi Z 2012 Nanoplasmonics: a frontier of photovoltaic solar cells Nanophotonics 1 235-48

[22] Singh U P and Patra S P 2010 Progress in Polycrystalline Thin-Film Cu(In,Ga)Se ${ }_{2}$ Solar Cells International Journal of Photoenergy 2010 468147/1-/19

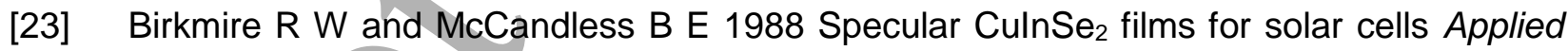
Physics Letters 53 140-1

[24] Negami T, Nishiwaki S, Hashimoto $Y$ and Kohara N 1998 Effect of absorber thickness on performance of $\mathrm{Cu}(\mathrm{In}, \mathrm{Ga}) \mathrm{Se}_{2}$ Solar Cells. In: 2nd World Conference on photovoltaic solar energy conversion

[25] Shafarman W N, Birkmire R W, Marsillac S, Marudachalam M, Orbey N and Russell T W F 1997 Effect of reduced deposition temperature, time, and thickness on $\mathrm{Cu}(\mathrm{InGa}) \mathrm{Se}_{2}$ films and devices. In: Photovoltaic Specialists Conference, 1997., Conference Record of the Twenty-Sixth IEEE 331-4

[26] Shafarman W N, Huang R S and Stephens S H 2006 Characterization of Cu(InGa)Se 2 Solar Cells using Etched Absorber Layers. In: 2006 IEEE 4th World Conference on Photovoltaic Energy Conference 420-3 
[27] Larsen J K, Simchi H, Xin P, Kim K and Shafarman W N 2014 Backwall superstrate configuration for ultrathin $\mathrm{Cu}(\mathrm{In}, \mathrm{Ga}) \mathrm{Se}_{2}$ solar cells Applied Physics Letters 104033901

[28] Ramanathan K, Noufi R, To B, Young D I, Bhattacharya R, Contreras M A, Dhere R G and Teeter G 2006 Processing and Properties of Sub-Micron CIGS Solar Cells. In: 2006 IEEE 4th World Conference on Photovoltaic Energy Conference 380-3

[29] Lundberg O, Bodegård M, Malmström J and Stolt L 2003 Influence of the Cu(In,Ga)Se thickness and $\mathrm{Ga}$ grading on solar cell performance Progress in Photovoltaics: Research and Applications 11 77-88

[30] Pettersson J, Törndahl T, Platzer-Björkman C, Hultqvist A and Edoff M 2013 The Influence of Absorber Thickness on $\mathrm{Cu}(\mathrm{In}, \mathrm{Ga}) \mathrm{Se}_{2}$ Solar Cells With Different Buffer Layers IEEE Journal of Photovoltaics 3 1376-82

[31] Gloeckler M and Sites J R 2005 Potential of submicrometer thickness Cu(In,Ga)Se ${ }_{2}$ solar cells J.Appl.Phys. 98 103703/1-/7

[32] Jehl Z, Erfurth F, Naghavi N, Lombez L, Gerard I, Bouttemy M, Tran-Van P, Etcheberry A, Voorwinden G, Dimmler B, Wischmann W, Powalla M, Guillemoles J F and Lincot D 2011 Thinning of CIGS solar cells: Part II: Cell characterizations Thin Solid Films 519 7212-5

[33] Jehl Li-Kao Z, Naghavi N, Erfurth F, Guillemoles J F, Gérard I, Etcheberry A, Pelouard J L, Collin S, Voorwinden G and Lincot D 2012 Towards ultrathin copper indium gallium diselenide solar cells: proof of concept study by chemical etching and gold back contact engineering Progress in Photovoltaics: Research and Applications 20 582-7

[34] Kim K, Park H, Kim W K, Hanket G M and Shafarman W N 2013 Effect of Reduced $\mathrm{Cu}(\mathrm{InGa})(\mathrm{SeS})_{2}$ Thickness Using Three-Step $\mathrm{H}_{2} \mathrm{Se} / \mathrm{Ar} / \mathrm{H}_{2} \mathrm{~S}$ Reaction of Cu-In-Ga Metal Precursor IEEE Journal of Photovoltaics 3 446-50

[35] Yin G, Brackmann V, Hoffmann V and Schmid M 2015 Enhanced performance of ultrathin $\mathrm{Cu}(\mathrm{In}, \mathrm{Ga}) \mathrm{Se}_{2}$ solar cells deposited at low process temperature Solar Energy Materials and Solar Cells 132 142-7

[36] van Lare C, Yin G, Polman A and Schmid M 2015 Light Coupling and Trapping in Ultrathin $\mathrm{Cu}(\mathrm{In}, \mathrm{Ga}) \mathrm{Se} 2$ Solar Cells Using Dielectric Scattering Patterns ACS Nano 9 9603-13

[37] Stuart H R and Hall D G 1998 Island size effects in nanoparticle-enhanced photodetectors Applied Physics Letters 73 3815-7

[38] Morawiec S, Mendes M J, Mirabella S, Simone F, Priolo F and Crupi I 2013 Self-assembled silver nanoparticles for plasmon-enhanced solar cell back reflectors: correlation between structural and optical properties Nanotechnology 24265601

[39] Pillai S, Catchpole K R, Trupke T and Green M A 2007 Surface plasmon enhanced silicon solar cells J.Appl.Phys. 101 093105/1-/8

[40] Frens G 1973 Controlled Nucleation for the Regulation of the Particle Size in Monodisperse Gold Suspensions Nature Physical Science 241 20-2

[41] Jana N R, Gearheart L and Murphy C J 2001 Wet chemical synthesis of silver nanorods and nanowires of controllable aspect ratio Chemical Communications 617-8 
[42] Brown K R, Walter D G and Natan M J 2000 Seeding of Colloidal Au Nanoparticle Solutions. 2. Improved Control of Particle Size and Shape Chemistry of Materials 12 30613

[43] Mulvaney P, Liz-Marzan L M, Giersig M and Ung T 2000 Silica encapsulation of quantum dots and metal clusters Journal of Materials Chemistry 10 1259-70

[44] Liu Y, Fu Y, Dittrich T, Sáez-Araoz R, Schmid M, Hinrichs V, Lux-Steiner M C and Fischer $\mathrm{C}-\mathrm{H} 2015$ Phase transitions during formation of $\mathrm{Ag}$ nanoparticles on $\mathrm{In}_{2} \mathrm{~S}_{3}$ precursor layers Thin Solid Films 590 54-9

[45] Fu Y, Sáez-Araoz R, Köhler T, Krüger M, Steigert A, Lauermann I, Lux-Steiner M C and Fischer C-H 2013 Spray-ILGAR ZnS nanodots/In $\mathrm{n}_{2} \mathrm{~S}_{3}$ as defect passivation/point contact bilayer buffer for $\mathrm{Cu}(\mathrm{In}, \mathrm{Ga})(\mathrm{S}, \mathrm{Se})_{2}$ solar cells Solar Energy Materials \& Solar Cells 117 293-9

[46] Liu Y, Plate P, Hinrichs V, Köhler T, Song M, Manley P, Schmid M, Dittrich T, Bartsch P, Fiechter S, Lux-Steiner M C and Fischer C-H 2016 Size and density controlled deposition of $\mathrm{Ag}$ nanoparticle films by a novel low temperature spray chemical vapor deposition method - research into mechanism and particle growth submitted

[47] Sakai N, Fujiwara Y, Takahashi Y and Tatsuma T 2009 Plasmon-resonance-based generation of cathodic photocurrent at electrodeposited gold nanoparticles coated with $\mathrm{TiO}_{2}$ films ChemPhysChem 10 766-9

[48] Ludwig W, Ohm W, Correa-Hoyos J-M, Zhao Y, Lux-Steiner M C and Gledhill S 2013 Electrodeposition parameters for ZnO nanorod arrays for photovoltaic applications physica status solidi (a) 210 1557-63

[49] Ohm W, Riedel W, Askünger Ü, Heinemann M D, Kaufmann C A, Garcia J L, Izquierdo V, Fontané X, Goislard T, Lux-Steiner M C and Gledhill S 2015 An overview of technological aspects of $\mathrm{Cu}(\mathrm{In}, \mathrm{Ga}) \mathrm{Se}_{2}$ solar cell architectures incorporating $\mathrm{ZnO}$ nanorod arrays physica status solidi (a) 212 76-87

[50] Yang S M, Jang S G, Choi D G, Kim S and Yu H K 2006 Nanomachining by Colloidal Lithography Small 2 458-75

[51] Hawker C J and Russell T P 2011 Block Copolymer Lithography: Merging "Bottom-Up" with "Top-Down" Processes MRS Bulletin 30 952-66

[52] Höflich K, Yang R B, Berger A, Leuchs G and Christiansen S 2011 The direct writing of plasmonic gold nanostructures by electron-beam-induced deposition Advanced materials 23 2657-61

[53] Chou S Y, Krauss P R and Renstrom P J 1996 Imprint Lithography with 25-Nanometer Resolution Science 272 85-7

[54] Guo L J 2007 Nanoimprint Lithography: Methods and Material Requirements Advanced materials 19 495-513

[55] Andreani L C, Kowalczewski P A, Mura C I, Patrini M, Acciarri M, Binetti S, Sassella A and Marchionna S 2012 Towards CIGS Solar Cells with Reduced Film Thickness: A Study of Optical Properties and of Photonic Structures for Light Trapping. In: 27th European Photovoltaic Solar Energy Conference and Exhibition 2334-7 
[56] Hwang S and Jang J-H 2012 3D Simulations for the Optimization of Antireflection Subwavelength Structures in CIGS Solar Cells. In: Photovoltaic Specialists Conference (PVSC), 2012 38th IEEE 000864-7

[57] Onwudinanti C, Vismara R, Isabella O, Grenet L, Emieux F and Zeman M 2016 Advanced light management based on periodic textures for $\mathrm{Cu}(\mathrm{In}, \mathrm{Ga}) \mathrm{Se}_{2}$ thin-film solar cells Optics Express 24 A693-707

[58] Liao Y-K, Wang Y-C, Yen Y-T, Chen C-H, Hsieh D-H, Chen S-C, Lee C-Y, Lai C-C, Kuo W-C, Juang J-Y, Wu K-H, Cheng S-J, Lai C-H, Lai F-I, Kuo S-Y, Kuo H-C and Chueh Y-L 2013 Non-antireflective Scheme for Efficiency Enhancement of $\mathrm{Cu}(\mathrm{In}, \mathrm{Ga}) \mathrm{Se}_{2}$ Nanotip Array Solar Cells ACS Nano 7 7318-29

[59] Liu C-H, Chen C-H, Chen S-Y, Yen Y-T, Kuo W-C, Liao Y-K, Juang J-Y, Kuo H-C, Lai CH, Chen L-J and Chueh Y-L 2011 Large Scale Single-Crystal Cu(In,Ga)Se $e_{2}$ Nanotip Arrays For High Efficiency Solar Cell Nano Letters 11 4443-8

[60] Wang Y-C, Cheng H-Y, Yen Y-T, Wu T-T, Hsu C-H, Tsai H-W, Shen C-H, Shieh J-M and Chueh Y-L 2015 Large-Scale Micro- and Nanopatterns of $\mathrm{Cu}(\mathrm{In}, \mathrm{Ga}) \mathrm{Se}_{2}$ Thin Film Solar Cells by Mold-Assisted Chemical-Etching Process ACS Nano 9 3907-16

[61] Wang W, Wu S, Knize R J, Reinhardt K, Lu Y and Chen S 2012 Enhanced photon absorption and carrier generation in nanowire solar cells Optics Express 20 3733-43

[62] Le D, Tran Q, Lee S and Kim S 2014 Ultra Broadband Absorption of SPPs Enhanced Dual Grating Thin Film CIGS Solar Cell Enabled by Particle Swarm Optimization Journal of the Optical Society of Korea 18 429-35

[63] Colin C, Cattoni A, Massiot I, Guillemoles J F, Bardou N, Dupuis C, Pelouard J-L, Mercier D, Gérard I, Etcheberry A, Jehl Z, Lincot D, Naghavi N and Collin S 2012 Broadband Light Trapping in Ultra-Thin Nano-Structured $\mathrm{Cu}(\mathrm{In}, \mathrm{Ga}) \mathrm{Se}_{2}$ Solar Cells. In: 27th European Photovoltaic Solar Energy Conference and Exhibition 2244 - 8

[64] Jeng M-J, Chen Z-Y, Xiao Y-L, Chang L-B, Ao J, Sun Y, Popko E, Jacak W and Chow L 2015 Improving Efficiency of Multicrystalline Silicon and CIGS Solar Cells by Incorporating Metal Nanoparticles Materials 8 6761-71

[65] Park S-U, Sharma R, Sim J-K, Baek B J, Ahn H-K, Kim J S and Lee C-R 2013 Development of gold induced surface plasmon enhanced CIGS absorption layer on polyimide substrate Applied Surface Science 280 757-63

[66] Londhe P U, Rohom A B and Chaure N B 2016 Improvement in the CIGS Solar Cell Parameters by Using Plasmonic (Au) Nanoparticle Nanoscience and Nanotechnology 6 43-6

[67] Chen S-C, Chen Y-J, Chen W T, Yen Y-T, Kao T S, Chuang T-Y, Liao Y-K, Wu K-H, Yabushita A, Hsieh T-P, Charlton M D B, Tsai D P, Kuo H-C and Chueh Y-L 2014 Toward Omnidirectional Light Absorption by Plasmonic Effect for High-Efficiency Flexible Nonvacuum Cu(In,Ga)Se 2 Thin Film Solar Cells ACS Nano 8 9341-8

[68] Schmid M, Klenk R, Lux-Steiner M C, Topic M and Krc J 2011 Modeling plasmonic scattering combined with thin-film optics Nanotechnology 22 025204/1-/10 
[69] Schmid M, Klaer J, Klenk R, Topič M and Krč J 2013 Stability of plasmonic metal nanoparticles integrated in the back contact of ultra-thin $\mathrm{Cu}(\mathrm{In}, \mathrm{Ga}) \mathrm{S}_{2}$ solar cells Thin Solid Films 527 308-13

[70] Yin G, Steigert A, Andrae P, Goebelt M, Latzel M, Manley P, Lauermann I, Christiansen S and Schmid M 2015 Integration of plasmonic Ag nanoparticles as a back reflector in ultrathin $\mathrm{Cu}(\mathrm{In}, \mathrm{Ga}) \mathrm{Se}_{2}$ solar cells Applied Surface Science 355 800-4

[71] Goffard J, Cattoni A, Mollica F, Jubault M, Colin C, Guillemoles J F, Lincot D, Naghavi N and Collin S 2015 Nanostructured Back Mirror for Ultra-Thin CIGS Solar Cell. In: EU PVSEC, (Hamburg

[72] Grandidier J, Weitekamp R A, Deceglie M G, Callahan D M, Battaglia C, Bukowsky C R, Ballif C, Grubbs R H and Atwater H A 2013 Solar cell efficiency enhancement via light trapping in printable resonant dielectric nanosphere arrays Physica Status Solidi (a) $\mathbf{2 1 0}$ 255-60

[73] Yin G, Manley P and Schmid M 2016 Light absorption enhancement for ultra-thin $\mathrm{Cu}\left(\operatorname{In}_{1-\mathrm{x}} \mathrm{Ga}_{\mathrm{x}}\right) \mathrm{Se}_{2}$ solar cells using closely packed 2-D SiO $\mathrm{S}_{2}$ nanosphere arrays Solar Energy Materials and Solar Cells 153 124-30

[74] Aé L, Kieven D, Chen J, Klenk R, Rissom T, Tang Y and Lux-Steiner M C 2010 ZnO nanorod arrays as an antireflective coating for $\mathrm{Cu}(\mathrm{In}, \mathrm{Ga}) \mathrm{Se}_{2}$ thin film solar cells Progress in Photovoltaics: Research and Applications 18 209-13

[75] Yin G, Knight M W, van Lare M-C, Solà Garcia M M, Polman A and Schmid M 2016 OptoElectronic Enhancement of Ultrathin CIGSe Solar Cells by Nanophotonic Contacts submitted

[76] Jackson P, Hariskos D, Wuerz R, Kiowski O, Andreas Bauer, Friedlmeier T M and Powalla M 2015 Properties of $\mathrm{Cu}(\mathrm{In}, \mathrm{Ga}) \mathrm{Se}_{2}$ solar cells with new record efficiencies up to $21.7 \%$ Physica Status Solidi RRL 9 28-31

[77] Schmid M, Yin G, Song M, Duan S, Heidmann B, Sancho-Martinez D, Kämmer S, Köhler T, Manley P and Lux-Steiner M C 2016 Concentrating light in $\mathrm{Cu}(\mathrm{In}, \mathrm{Ga}) \mathrm{Se}_{2}$ solar cells Proc. of SPIE Next Generation Technologies for Solar Energy Conversion VII 9937 993703-1 - -7

[78] Yin G, Song M, Duan S, Manley P, Greiner D, Kaufmann C and Schmid M 2016 WellControlled Dielectric Nanomeshes by Colloidal Nanosphere Lithography for OptoElectronic Enhancement of Ultrathin $\mathrm{Cu}(\mathrm{In}, \mathrm{Ga}) \mathrm{Se}_{2}$ Solar Cells ACS Appl. Materials \& Interfaces 831648

[79] Schmid M, van Lare M-C, Yin G and Polman A 2016 Unerschöpfliche Energie - Lichtfänger für ultra-dünne $\mathrm{Cu}(\mathrm{In}, \mathrm{Ga}) \mathrm{Se}_{2}$-Solarzellen GIT Labor-Fachzeitschrift 2 36-8

[80] Vermang B, Fjällström V, Pettersson J, Salomé P and Edoff M 2013 Development of rear surface passivated $\mathrm{Cu}(\mathrm{In}, \mathrm{Ga}) \mathrm{Se}_{2}$ thin film solar cells with nano-sized local rear point contacts Solar Energy Materials and Solar Cells 117 505-11

[81] Vermang B, Watjen J T, Fjallstrom V, Rostvall F, Edoff M, Kotipalli R, Henry F and Flandre D 2014 Employing Si solar cell technology to increase efficiency of ultra-thin $\mathrm{Cu}(\mathrm{In}, \mathrm{Ga}) \mathrm{Se}_{2}$ solar cells Progress in Photovoltaics: Research and Applications 22 1023-9 
[82] Vermang B, Wätjen J T, Fjällström V, Rostvall F, Edoff M, Gunnarsson R, Pilch I, Helmersson U, Kotipalli R, Henry F and Flandre D 2015 Highly reflective rear surface passivation design for ultra-thin $\mathrm{Cu}(\mathrm{In}, \mathrm{Ga}) \mathrm{Se}_{2}$ solar cells Thin Solid Films 582 300-3

[83] Casper P, Hünig R, Gomard G, Kiowski O, Reitz C, Lemmer U, Powalla M and Hetterich M 2016 Optoelectrical improvement of ultra-thin $\mathrm{Cu}(\mathrm{In}, \mathrm{Ga}) \mathrm{Se}_{2}$ solar cells through microstructured $\mathrm{MgF}_{2}$ and $\mathrm{Al}_{2} \mathrm{O}_{3}$ back contact passivation layer physica status solidi (RRL) - Rapid Research Letters 10 376-80

[84] Allsop N, Nürnberg R, Lux-Steiner M C and Schedel-Niedrig T 2009 Three-dimensional simulations of a thin film heterojunction solar cell with a point contact/defect passivation structure at the heterointerface Applied Physics Letters 95 122108-10

[85] Reinhard P, Bissig B, Pianezzi F, Hagendorfer H, Sozzi G, Menozzi R, Gretener C, Nishiwaki S, Buecheler S and Tiwari A N 2015 Alkali-Templated Surface Nanopatterning of Chalcogenide Thin Films: A Novel Approach Toward Solar Cells with Enhanced Efficiency Nano Letters 15 3334-40 